\title{
A Review of Piezoelectric Vibration Energy Harvesting with Magnetic Coupling Based on Different Structural Characteristics
}

\author{
Junxiang Jiang ${ }^{1,2}$, Shaogang Liu ${ }^{1, * \mathbb{C}}$, Lifeng Feng ${ }^{3}$ and Dan Zhao ${ }^{1}$ \\ 1 College of Mechanical and Electrical Engineering, Harbin Engineering University, Harbin 150001, China; \\ jiangjunxiang2014@163.com (J.J.); heuzhaodan@outlook.com (D.Z.) \\ 2 School of Mechanical and Civil Engineering, Jilin Agricultural Science and Technology University, \\ Jilin 132101, China \\ 3 Beijing Institute of Precision Mechatronics and Controls, CALT, Beijing 100076, China; feng_lifeng@yeah.net \\ * Correspondence: liu_shaogang@hotmail.com
}

check for updates

Citation: Jiang, J.; Liu, S.; Feng, L.; Zhao, D. A Review of Piezoelectric Vibration Energy Harvesting with Magnetic Coupling Based on Different Structural Characteristics. Micromachines 2021, 12, 436. https: / / doi.org/10.3390/mi12040436

Academic Editor: Ju-Hyuck Lee

Received: 7 March 2021

Accepted: 7 April 2021

Published: 14 April 2021

Publisher's Note: MDPI stays neutral with regard to jurisdictional claims in published maps and institutional affiliations.

Copyright: (c) 2021 by the authors. Licensee MDPI, Basel, Switzerland. This article is an open access article distributed under the terms and conditions of the Creative Commons Attribution (CC BY) license (https:/ / creativecommons.org/licenses/by/ $4.0 /)$.

\begin{abstract}
Piezoelectric vibration energy harvesting technologies have attracted a lot of attention in recent decades, and the harvesters have been applied successfully in various fields, such as buildings, biomechanical and human motions. One important challenge is that the narrow frequency bandwidth of linear energy harvesting is inadequate to adapt the ambient vibrations, which are often random and broadband. Therefore, researchers have concentrated on developing efficient energy harvesters to realize broadband energy harvesting and improve energy-harvesting efficiency. Particularly, among these approaches, different types of energy harvesters adopting magnetic force have been designed with nonlinear characteristics for effective energy harvesting. This paper aims to review the main piezoelectric vibration energy harvesting technologies with magnetic coupling, and determine the potential benefits of magnetic force on energy-harvesting techniques. They are classified into five categories according to their different structural characteristics: monostable, bistable, multistable, magnetic plucking, and hybrid piezoelectric-electromagnetic energy harvesters. The operating principles and representative designs of each type are provided. Finally, a summary of practical applications is also shown. This review contributes to the widespread understanding of the role of magnetic force on piezoelectric vibration energy harvesting. It also provides a meaningful perspective on designing piezoelectric harvesters for improving energy-harvesting efficiency.
\end{abstract}

Keywords: piezoelectric energy harvester; vibration; magnetic coupling; energy-conversion device

\section{Introduction}

Vibration sources can be found in different environments ranging from human motion, bridges, industrial equipment, and vehicle vibration to household appliances, etc. Energy-harvesting techniques that convert ambient vibrations into electrical energy for charging self-powered electronic devices have attracted a lot of attention over the past decade [1-4]. For vibration-based energy harvesters, there are mainly four different methods that are most extensively used by scholars in the process of research and application, including piezoelectric [5-8], electrostatic [9-11], electromagnetic [12-14], and triboelectric transductions [15-17]. Piezoelectric energy harvesting is popular due to the merits of high energy density, easy miniaturization, simple structure, and easy application characteristics of piezoelectric materials. In many real applications, ambient vibration frequencies are often random and broadband, and the design of energy harvesters needs to adapt to these vibration characteristics. The key issue is how to make the frequency of a harvester match the external frequency with a wider frequency bandwidth for applications.

In general, the performance of linear piezoelectric energy harvesting is limited to a very narrow frequency bandwidth [18-20]. So, many methods have been proposed to realize broadband energy harvesting and improve energy-harvesting efficiency, including multimodal [21,22], frequency tuning [23-25], frequency-up [26-29], nonlinear 
approaches [30-34], etc. In addition, the design of new piezoelectric materials, such as organic-inorganic nanocomposites, is a promising strategy for improving the energyconversion efficiencies. Many methods for the improvement of the piezoelectric response of polymeric materials and scaffolds have been developed by materials scientists [35]. Among various piezoelectric energy-harvesting structures, permanent magnets are often attached to associated structures to improve structural properties. It is easy to design a nonlinear energy harvester with magnetic coupling, with characteristics such as magnetic frequency tuning [36-38], magnetic frequency up-conversion [39-43], monostable [44,45], bistable [46-48], and multistable [49-53]. Bouhedma et al. presented a novel vibrationbased piezoelectric energy harvester with magnetic frequency-tuning [54]. Compared with a single-frequency harvester, the frequency of this harvester can be tuned by up to $18 \%$ both up and down. The presented approach combining multiresonance and frequency tunability acquired a larger operative bandwidth. Yang et al. presented a press-button-type piezoelectric energy harvester, in which the frequency upconversion concept was adopted to generate high power density [55]. The converted energy was magnified by an impact between magnets. Cottone and Gammaitoni proposed a bistable oscillator for a generic wide-spectrum vibration [56]. The dynamics of this harvester could be controlled with the magnetic force and polarities of the added magnets. There was a range of distances between magnets, and the voltage reached a maximum value under random excitations. The output power was improved between 400 and $600 \%$ compared to the linear one in experiments. Tang et al. investigated the functionality of vibration energy harvesters using magnets. Both monostable and bistable configurations introduced by magnets were discussed with various excitation levels to improve the performance of vibration energy harvesting [57]. Zhou et al. investigated the dynamic characteristics of broadband tristable energy harvesters with magnetic coupling [58]. Compared with the bistable state, the results showed that this harvester was easily excited to pass potential wells for producing high energy output over a wider range of frequencies. Wang et al. proposed a wideband quin-stable energy harvester with magnetic nonlinearity [59].

In addition, magnets are usually arranged to pluck the piezoelectric beam with a repelling or an attractive configuration [60-63]. Relative movement of the magnet in relation to the coil causes a variation magnetic flux inside the coil, and the voltage induced in the coil can be obtained by Faraday's law. This hybrid approach increases the power generation capability of the energy harvester due to the combinational piezoelectric and electromagnetic operation under the same external excitation [64-66].

Moreover, a new generation of devices can be developed using multiferroic materials and structures based on magnetoelectric effects. Magnetoelectric effects in ferromagneticferroelectric layered composites arise due to magnetostriction and the piezoelectric effect in the ferroic phases, and these structures are driven by mechanical strain. Compared with the mechanical method of piezotronics, such a magnetic-field-based method via magnetoelectric coupling effects has some important advantages because it is remote and contactless. Multiferroic composites have the potential for applications in sensors, autonomous energy sources, electrically controlled microwave devices, and memory elements [67-71].

There are some published reviews about piezoelectric energy harvesting, and yet most of them are primarily focused on topics including biomedicine [72-77], micro-electromechanical-systems (MEMS) [78-82], nanogenerators [83-85], materials [86-90], and variety energy harvesting [81-94]. However, this review focuses on the piezoelectric vibration energy harvesters with magnetic coupling. This review aims to classify five piezoelectric vibration energy harvesting technologies with magnetic coupling and determine the potential benefits of magnetic force on energy-harvesting techniques. We mainly focus on vibration energy sources in mechanical vibrations and human activities, and did not include flow energy sources like wind, sound, or ocean energy in this paper. In the analysis of different designs of energy-harvesting system, it is favorable to develop a harvester including magnets to enhance the efficiency of energy harvesting from vibrations to convert them to electrical energy. This paper will also discuss the applications of different energy- 
harvesting devices with magnetic coupling. The detailed introduction and application of the harvesters are discussed in the following sections.

A comprehensive review of recent studies on piezoelectric vibration energy harvesting is presented. Then, it is shown that magnetic force plays an important role in energy harvesting. This review is organized as follows. The second to sixth sections illustrates detailed descriptions of the five types of piezoelectric vibration energy harvesting technologies with magnetic coupling, including monostable, bistable, multistable, magnetic plucking, and hybrid piezoelectric-electromagnetic methods. Working principles and representative designs are also displayed in these sections. Then, the practical applications of the harvesters are generalized in the seventh section. The last section summarizes this review and discusses the outlook for piezoelectric energy harvesting.

\section{Monostable Energy Harvesters}

\subsection{Working Mechanism}

Wider bandwidth for energy harvesting can be achieved by proper sweep or by magnet spacing, especially for the hardening or softening configurations, according to the forced Duffing equation. A monostable nonlinear energy harvester can be implemented using magnetic repulsion and magnetic attraction [95-98]. It is divided into the magnet parallel to the piezoelectric beam and perpendicular to the piezoelectric beam, based on the arrangement of magnets and piezoelectric beams.

The dynamic behavior for vibration energy harvesters can be described by a model, known as the Duffing oscillator. To gain a more general understanding, a physics-based model consisting of a lumped-parameter mechanical oscillator coupled with an electromechanical coupling was established [48,99,100].

The nondimensional equations of motion can be expressed as Equations (1) and (2).

$$
\begin{gathered}
\ddot{x}+2 \zeta \dot{x}+\frac{d U}{d x}+\kappa^{2} y=-\ddot{x}_{b} \\
\dot{y}+\alpha y=\dot{x}
\end{gathered}
$$

where

$$
\frac{d U}{d x}=(1-r) x+\delta x^{3}
$$

where the second derivative of $x_{b}$ is the base acceleration, $x$ represents the relative displacement of the mass, $y$ is the electric quantity representing the induced voltage in capacitive harvesters, $\zeta$ is the mechanical damping ratio, $\kappa$ is a linear dimensionless electromechanical coupling coefficient, $\alpha$ is the ratio between the mechanical and electrical time constants of the harvester, $U$ represents the potential energy of the mechanical subsystem that leads to cubic nonlinearities in the mechanical oscillator, $r$ is introduced to permit variations in the linear stiffness around its nominal value, and $\delta$ is the coefficient of the cubic nonlinearity.

The form of Equation (3) divides energy harvesters into three major categories based on the shape of their potential energy function. When $\delta=0$ and $r<1$, the system is a linear harvester. When $\delta>0$ and $r \leq 1$, the system is a monostable hardening type. When $\delta<0$ and $r \leq 1$, the system is a monostable softening type. When $\delta>0$ and $r>1$, the system is a nonlinear bistable one. The potential function of the harvester has two potential wells separated by a potential barrier. For the monostable harvesters, the frequency-response curves bend which can make the bandwidth of energy harvesters wider. 


\subsection{Magnets Parallel to the Piezoelectric Beam}

For this kind of monostable-type piezoelectric energy harvester, the magnets are arranged in parallel with the piezoelectric beam [101-103]. Yang et al. developed a broadband vibration energy harvester based on a soft magneto-sensitive elastomer (SMSE), which was attached a polyvinylidene fluoride (PVDF) to convert vibration energy into electricity [104] (Figure 1). The device exhibited a strong softening effect when it was subjected to the magnetic field. When the load resistance was $4.7 \mathrm{M} \Omega$ and the SMSE thicknesses was $5 \mathrm{~mm}$, the corresponding power was $0.11 \mu \mathrm{W}$ over a wide frequency range at an acceleration level of $0.3 \mathrm{~g}$. Deng and Wang reported an input-dependent performance study of a nonlinear piezoelectric energy harvester with introduced magnetic interaction [105]. The performances of this harvester with two external magnet arrays (I and II) were compared. The harvester of Array II, which had a symmetric magnetic force, yielded better voltage output under a frequency sweep test. Compared with the linear one, the output voltage improved $104.5 \%$ and the bandwidth was $7 \mathrm{~Hz}$ under the excitation of $0.334 \mathrm{~g}$.

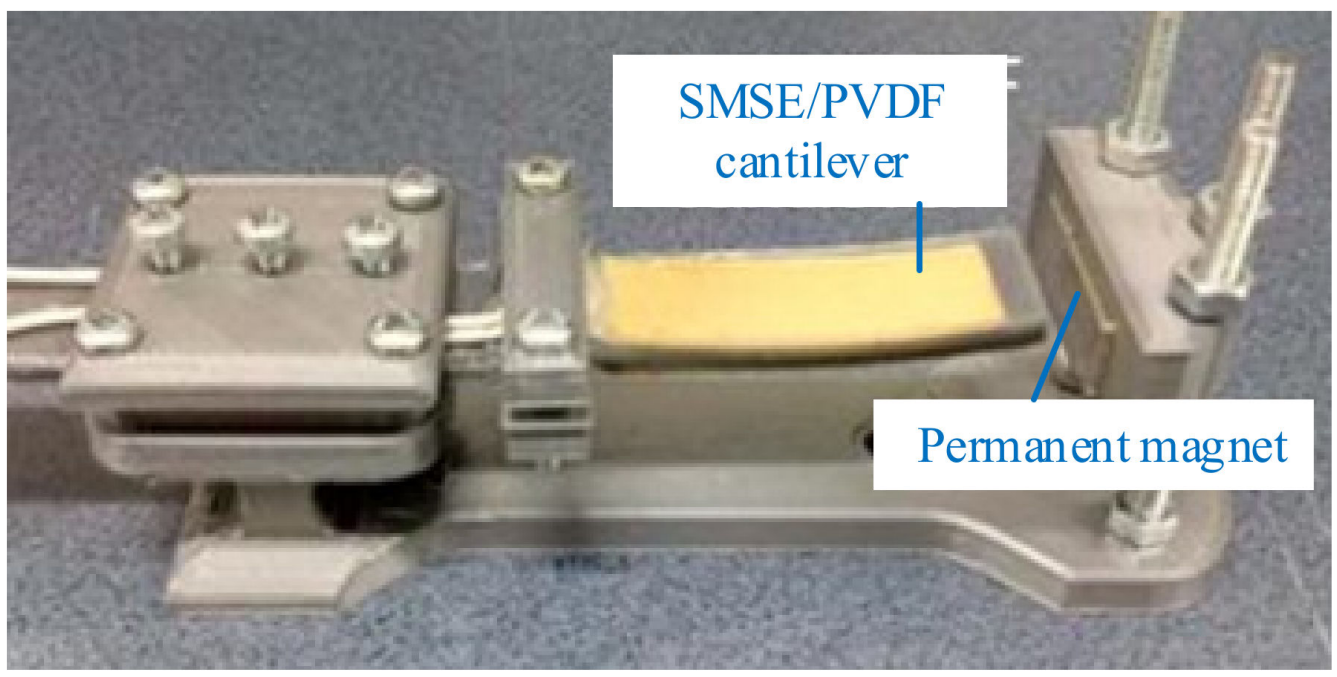

Figure 1. A soft magneto-sensitive elastomer (SMSE) harvester (reproduced with permission from [104]; published by IOP, 2018).

In addition, a two degrees of freedom (2-DOF) system has been studied by scholars. Krishnasamy et al. proposed a 2-DOF harvester to combine multimodal energy harvesting with the nonlinear vibration technique [106-108]. By properly choosing the structural parameters and the distance between the magnets, two resonant response peaks could be tuned to be close enough and with adequate amplitude. Upadrashta and Yang proposed an array of nonlinear piezomagnetoelastic energy harvesters for scavenging electrical energy from broadband vibrations with low amplitudes [109]. The dynamic responses of two harvesters, one with an attractive configuration and the other one with a repulsive configuration, were combined to achieve a bandwidth of $3.3 \mathrm{~Hz}$ at a power level of $100 \mu \mathrm{W}$ under harmonic excitation of $2 \mathrm{~m} / \mathrm{s}^{2}$.

The harvester may exhibit internal resonance, when the linear natural frequencies are commensurable or nearly commensurable $[110,111]$. To improve the frequency bandwidth, an L-shaped 2:1 internal piezoelectric harvester energy with frequency tuning magnets was proposed by Chen et al. [112]. Xiong et al. developed a 2:1 internal resonance harvester with magnetic interaction and an auxiliary oscillator for enhancing broadband vibration energy harvesting [113]. Yang and Towfighian proposed a 2-DOF harvester consisting of two resonators, each with a permanent magnet on its tip. Internal resonance could be triggered by adjusting the distance between two magnets [114] (Figure 2). 


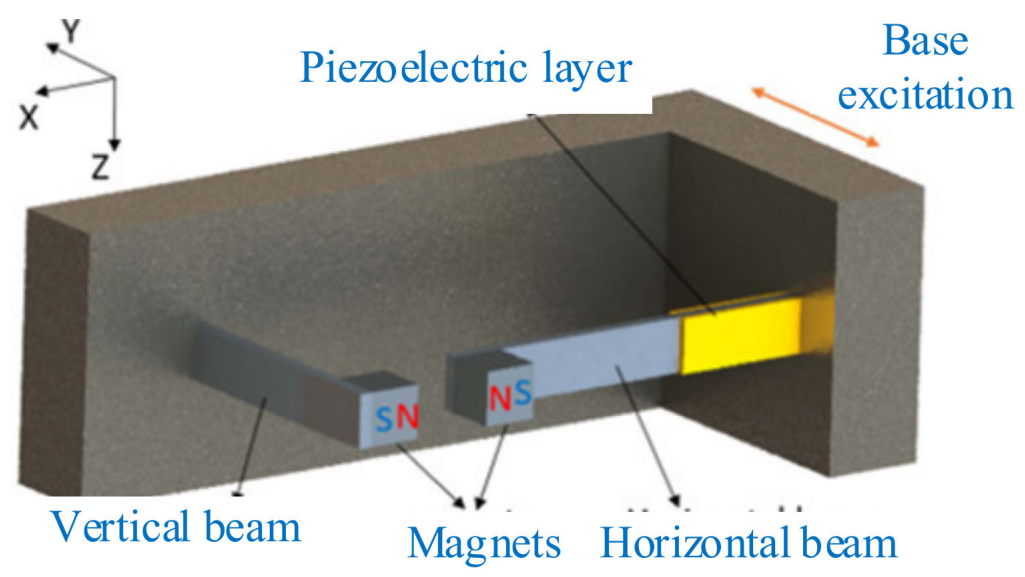

Figure 2. An internal resonance harvester formed by two beams (reproduced with permission from [114]; published by IOP, (2017).

\subsection{Magnets Perpendicular to the Piezoelectric Beam}

For this kind of monostable type piezoelectric energy harvester, the magnets are perpendicular to the piezoelectric beam [115-121]. Stanton et al. modeled and experimentally validated a nonlinear energy harvester capable of bidirectional hysteresis [122] (Figure 3a). By tuning nonlinear magnetic interactions around the end mass, hardening or softening responses occurred, increasing the bandwidth of the device in either direction. For the same exciting amplitude of $0.3 \mathrm{~g}$, the exciting frequency was linearly decreased for both the nonlinear and linear configurations. Figure 4a shows that the monostable harvester has a wider bandwidth in comparison to the linear beam. Shih and Su proposed a magnet-induced nonlinear U-shaped bidirectional piezoelectric harvester to overcome narrow bandwidth and unidirectional acquisition [123] (Figure 3b). A strong hardening effect could be observed in horizontal excitations when the magnet gap was small.

A combination of monostable, hybrid methods was applied to structural design. Fan et al. presented a monostable harvester for achieving enhanced energy from low-level excitations by introducing symmetric magnetic attraction and a pair of stoppers to confine the maximum deflection of the beam [124,125] (Figure 3c). The experimental results showed that the proposed device outperformed its linear counterpart in terms of output power ( $253 \%$ increase) and operating bandwidth ( $54 \%$ increase) under a sinusoidal vibration with an acceleration of $3 \mathrm{~m} / \mathrm{s}^{2}$. The monostable harvester exhibited not only a much wider bandwidth, but also a significantly larger peak voltage than the linear one when $D$ was $22 \mathrm{~mm}$ and $d$ was $8.7 \mathrm{~mm}$, as shown in Figure $4 \mathrm{~b}$. Zhang et al. presented a magnetically levitated harvester with a 2-DOF cantilever to performance dependence on initial free-end levitation position [126]. It was found that the case above the horizontal orientation had a stronger impact on the performance than that below the horizontal orientation. Moreover, the former brought a more significant influence on the second resonance frequency than the first one. The dynamic performances were affected by the initial free-end levitation position.

\subsection{Characteristic Analysis of the Monostable Harvesters}

The monostable energy harvester is constructed in a variety of flexible ways, including different magnet arrangements, attraction or repulsion, number of beams, etc. Table 1 illustrates the performances of some existing monostable type piezoelectric harvesters in recent years. It can be observed clearly that both types of magnet arrangement (parallel and perpendicular) are widely used, but there are some exceptions. Yang and Towfighian introduced magnetic nonlinearity to a 2-DOF system by combining the softening and hardening behaviors [103]. Two piezoelectric cantilevers with magnets were used. One cantilever was in the horizontal plane, but the other was in the vertical direction. The frequency bandwidth of this harvester was widened by the introduced magnetic nonlinearity, which decreased the threshold excitation value. 


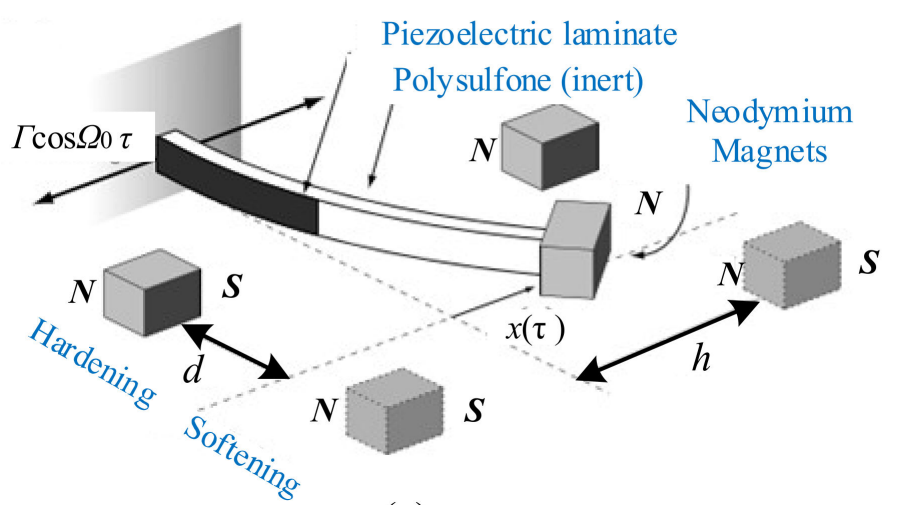

(a)

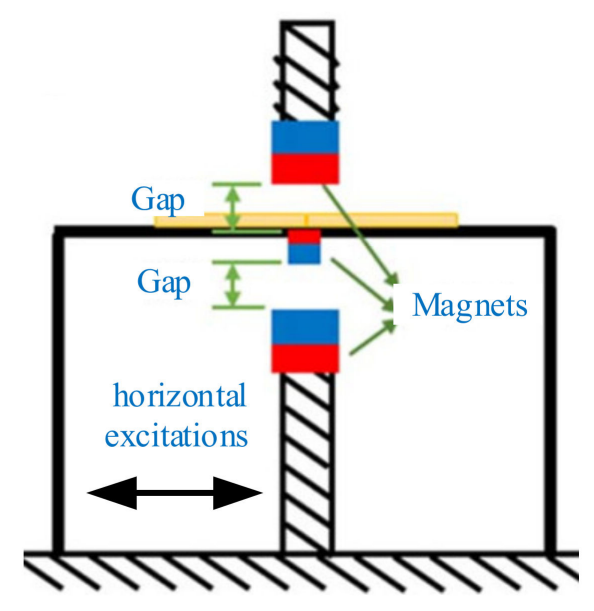

(b)

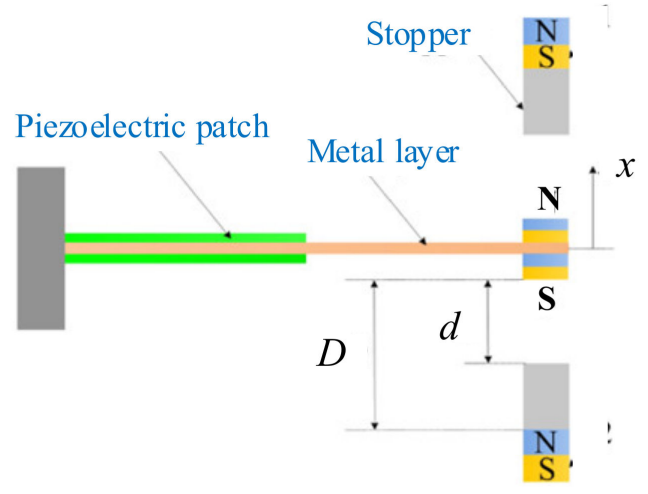

(c)

Figure 3. The monostable harvesters with the magnets perpendicular to the piezoelectric beam. (a) Magnetopiezoelastic energy harvester (reproduced with permission from [122]; published by American Institute of Physics, (2009). (b) U-shaped bidirectional harvester (reproduced with permission from [123]; published by IOP, 2018). (c) Monostable energy harvester (reproduced with permission from [125]; published by AIP, 2018).

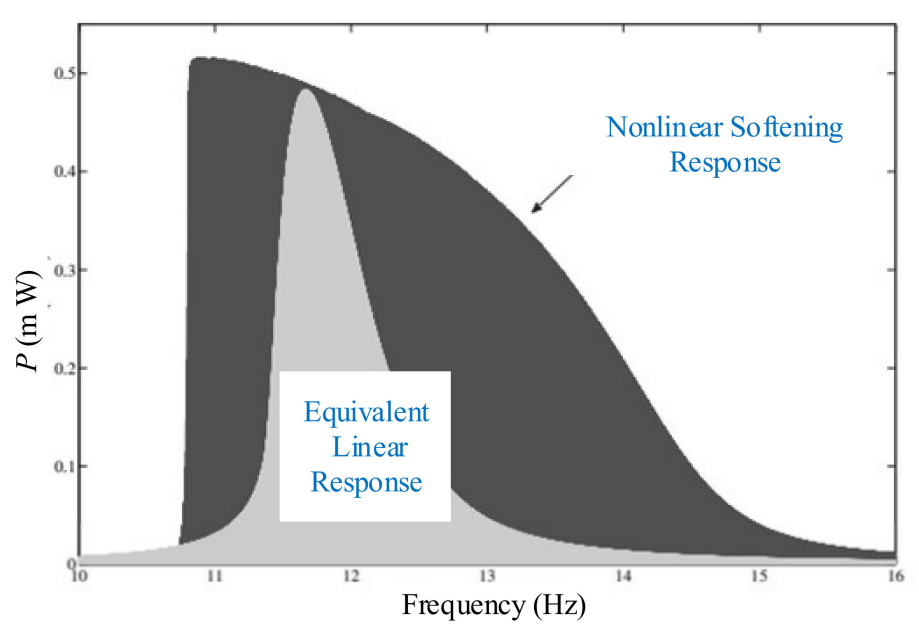

(a)

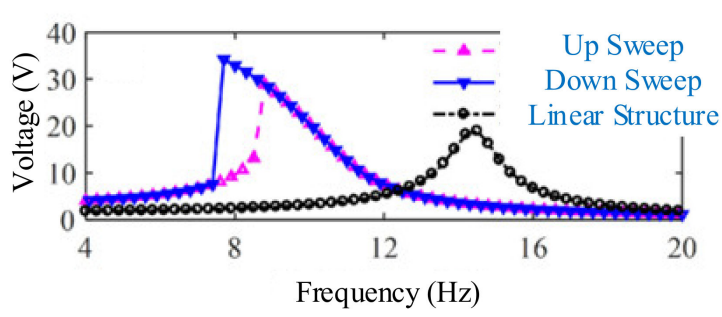

(b)

Figure 4. Nonlinear and linear energy-harvest responses. (a) The research results by Stanton et al. (reproduced with permission from [122]; published by American Institute of Physics, 2009). (b) The research results by Fan et al. (reproduced with permission from [125]; published by AIP, 2018). 
Table 1. Characteristics of some existing monostable-type piezoelectric harvesters.

\begin{tabular}{|c|c|c|c|c|c|c|}
\hline Reference & Year & Piezoelectric & Base Layer & Magnet Arrangement & Magnetic & Nonlinear Effect \\
\hline $\begin{array}{l}\text { Upadrashta } \\
\text { and Yang [109] }\end{array}$ & 2016 & MFC & Aluminium & Parallel & $\begin{array}{l}\text { Attraction and } \\
\text { repulsion }\end{array}$ & $\begin{array}{c}\text { Combining softening } \\
\text { and hardening }\end{array}$ \\
\hline $\begin{array}{l}\text { Krishnasamy } \\
\text { et al. [107] }\end{array}$ & 2018 & MPC & Aluminium & Parallel & $\begin{array}{l}\text { Attraction or } \\
\text { repulsion }\end{array}$ & $\begin{array}{l}\text { Antiresonance and } \\
\text { internal resonance }\end{array}$ \\
\hline Yang et al. [104] & 2019 & PVDF & SMSE & Parallel & Attraction & Softening \\
\hline $\begin{array}{l}\text { Cai and Harne } \\
\text { [101] }\end{array}$ & 2019 & PZT-5 H & Laminated & Parallel & Repulsion & $\begin{array}{l}\text { A trapezoidal beam } \\
\text { and nonlinearity }\end{array}$ \\
\hline $\begin{array}{c}\text { Yang and } \\
\text { Towfighian } \\
\text { [103] }\end{array}$ & 2019 & M2807P2 & Polymeric & $\begin{array}{c}\text { Parallel or } \\
\text { perpendicular }\end{array}$ & Repulsion & $\begin{array}{c}\text { Combining softening } \\
\text { and hardening }\end{array}$ \\
\hline $\begin{array}{l}\text { Chen et al. } \\
\text { [112] }\end{array}$ & 2016 & PZT-5 A & Stainless steel & Parallel & Attraction & $\begin{array}{c}\text { The L-shaped } \\
\text { internal resonant } \\
\text { harvester }\end{array}$ \\
\hline $\begin{array}{c}\text { Yang and } \\
\text { Towfighian } \\
\text { [114] }\end{array}$ & 2017 & PZT-5 A & Polymeric & Parallel & Repulsion & $\begin{array}{l}\text { The two degrees of } \\
\text { freedom internal } \\
\text { resonant harvester }\end{array}$ \\
\hline $\begin{array}{c}\text { Zhang et al. } \\
\text { [126] }\end{array}$ & 2017 & PZT & $\mathrm{E}=206 \mathrm{GPa}$ & Perpendicular & Repulsion & $\begin{array}{l}\text { Dependence on } \\
\text { initial free-end } \\
\text { levitation position }\end{array}$ \\
\hline $\begin{array}{l}\text { Abdelmoula } \\
\text { et al. [95] }\end{array}$ & 2017 & $\begin{array}{c}\mathrm{d}_{31}=-170 \\
\mathrm{pC} / \mathrm{N}\end{array}$ & Aluminum & Perpendicular & Attraction & $\begin{array}{l}\text { Softening or } \\
\text { hardening }\end{array}$ \\
\hline Rui et al. [97] & 2018 & MFC & $\begin{array}{l}\text { Aluminum } \\
\text { alloy }\end{array}$ & Perpendicular & $\begin{array}{l}\text { Repulsion } \\
\text { Attraction }\end{array}$ & $\begin{array}{l}\text { Hardening } \\
\text { Softening }\end{array}$ \\
\hline Fan et al. [125] & 2018 & PZT-5 H & Brass & Perpendicular & Attraction & $\begin{array}{l}\text { Softening and } \\
\text { stoppers }\end{array}$ \\
\hline $\begin{array}{c}\text { Shih and Su } \\
\text { [123] }\end{array}$ & 2019 & M-2807-P2 & $\mathrm{E}=205 \mathrm{GPa}$ & Perpendicular & $\begin{array}{l}\text { Attraction and } \\
\text { repulsion }\end{array}$ & $\begin{array}{l}\text { In two orthogonal } \\
\text { directions }\end{array}$ \\
\hline
\end{tabular}

The nonlinear magnetic force is complex and it depends on many variables, such as spacing distance between the magnets, polarity of magnets, and their dimensions. Abdelmoula et al. performed a comparative study on a broadband piezoelectric energy harvester with single and dual magnetic forces [95]. The results showed that hardening behaviors took place in the dual attractive magnets, but softening behaviors took place in the single-magnet design. Rui et al. studied four different harvester modes containing low/high frequency beams with attraction/repulsion [97]. A low beam with repulsion mode was selected due to its high output power in a wide operating frequency range. In addition, the internal resonance phenomenon can occur due to a nonlinear configuration using magnets.

\section{Bistable Energy Harvesters}

\subsection{Working Mechanism}

Compared to the monostable system, the main advantage of the bistable system lies in the fact that the interwell motion can lead to a large deformation, and then generate greater output power. However, the dynamics of the bistable configuration are more complicated than those of the monostable one. Small-amplitude oscillations in one potential well, largeamplitude oscillations crossing two potential wells, or even chaotic responses may appear, depending on the base excitation level and the initial condition. Magnetic attraction or magnetic repulsion can induce the bistability [127-135].

A typical bistable nonlinear piezoelectric energy harvester is shown in Figure 5a [136]. Two magnets were used to generate a repulsive force. The magnetic force is approximated as a cubic function that makes the system monostable or bistable, depending on the distance between the magnetic proof mass and fixed magnet. The horizontal component of the 
magnetic force is neglected due to the small tip displacement of the beam, and the vertical component can be obtained by Equation (4), as shown in Figure 5b.

$$
F_{m a g v}=F_{m a g} \sin \theta=F_{m a g} \frac{\tan \theta}{\sqrt{1+\tan ^{2} \theta}}=\frac{F_{m a g}}{d} \frac{z}{\sqrt{1+\left(\frac{z}{d}\right)^{2}}}
$$

where $F_{\text {mag }}$ is the magnetic force, $F_{\text {magv }}$ is the vertical component of magnetic force, $d$ is the distance between the two magnets, and $z$ is the relative displacement of the magnetic proof mass. Equation (4) is expanded using the Taylor's series method, and only the first two terms are considered because the contribution of the higher terms is negligible.

$$
F_{m a g v} \cong \frac{F_{m a g} z}{d}-\frac{F_{m a g} z^{3}}{2 d^{3}}
$$

where

$$
\frac{F_{m a g}}{d}=K_{1}, \frac{F_{m a g}}{2 d^{3}}=K_{2}
$$

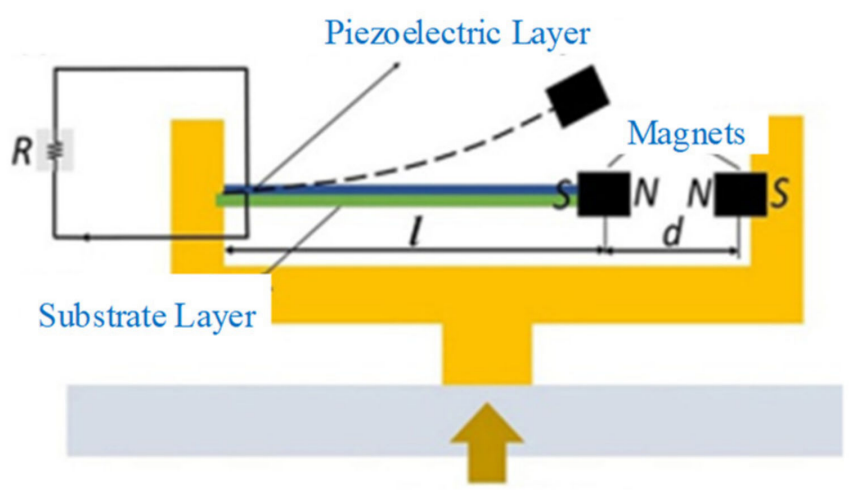

Base Excitation

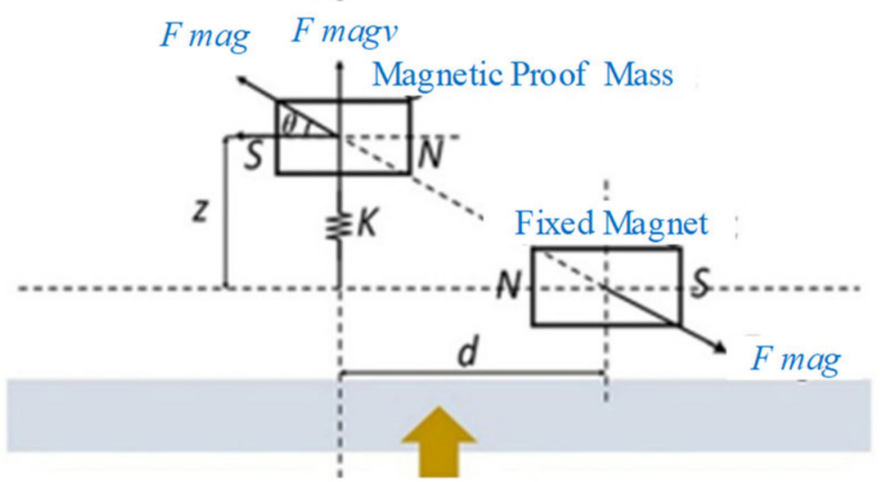

Base Excitation

(a)

(b)

Figure 5. (a) Schematic of piezoelectric cantilever beam with magnetic proof mass (reproduced with permission from [136]; published by Wiley-VCH Verlag GmbH \& Co. KGaA, Weinheim, 2015. (b) Free-body diagram of magnets (reproduced with permission from [136]; published by Wiley-VCH Verlag GmbH \& Co. KGaA, Weinheim, 2015.

When the beam vibrates from the equilibrium position, a restoring force due to the linear stiffness of the beam acts downward, and a counteracting restoring magnetic force acts in the upward direction. The net nonlinear force $F(z)$ is:

$$
F(z)=\left(K-K_{1}\right) z+K_{2} z^{3}
$$

The potential energy function of the piezoelectric system is given as:

$$
U(z)=\frac{1}{2}\left(K-K_{1}\right) z^{2}+\frac{1}{4} K_{2} z^{4}
$$

where $K=$ linear stiffness.

According to Equation (3), for $K-K_{1}<0$ and $K_{2}>0$, a bistable configuration is achieved. Bistable oscillators have a unique double-well restoring force potential [46]. The bistable devices may exhibit intrawell, chaotic, or interwell dynamics, depending on the initial conditions and exciting magnitude and frequency. The periodic interwell dynamics, alternatively high energy orbits or snap-through, have been recognized to dramatically improve energy-harvesting performances. However, the required velocity of the device is much greater than intrawell or chaotic dynamics. 
The generated average power during harmonic base excitation of bistable beams and the linear rectangular one (without considering nonlinearity in stiffness) were plotted in Figure 6. It showed bistable piezoelectric beams could generate substantially higher power values over a wide range of vibration frequencies compared with the linear one [136].

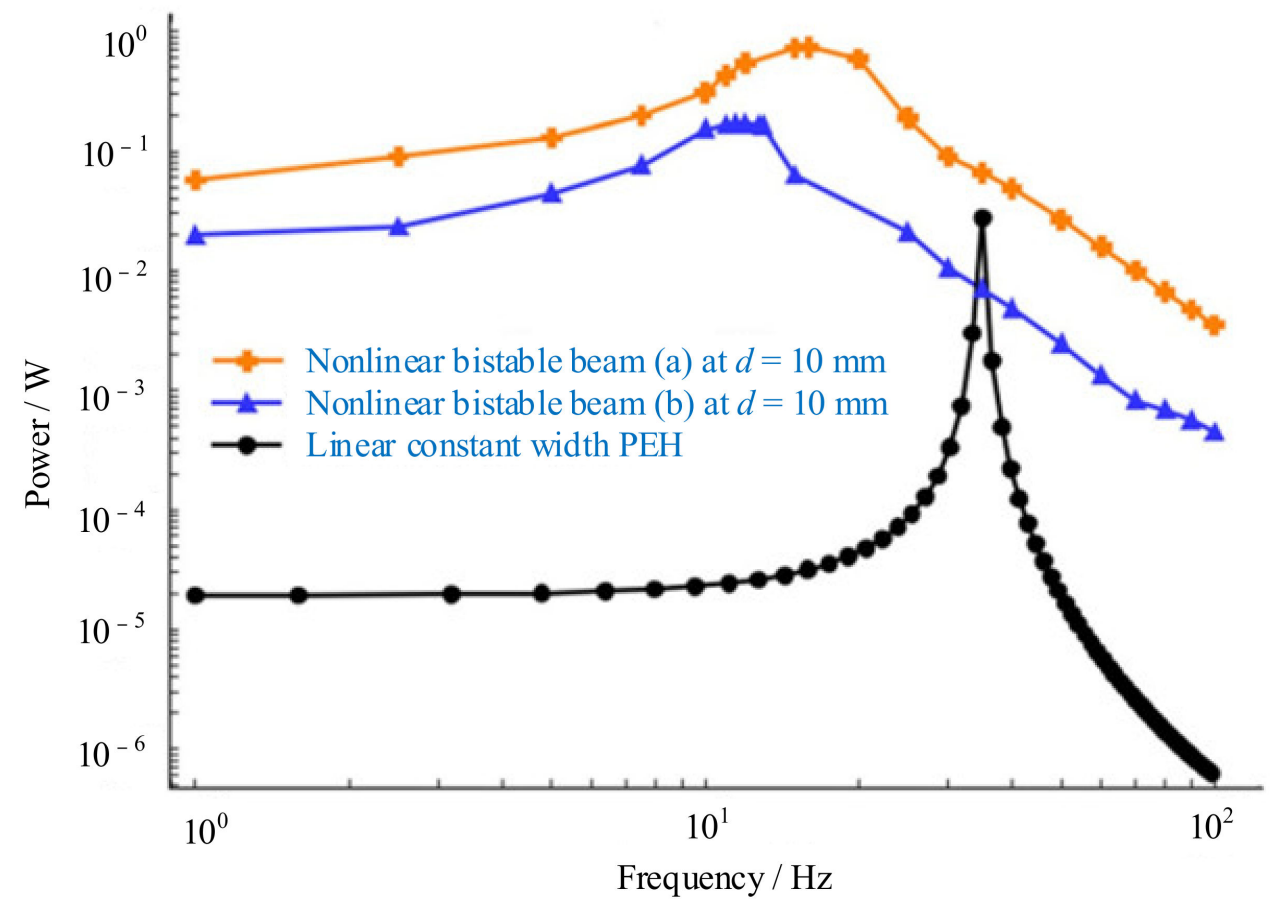

Figure 6. Power generated by bistable and linear harvesters at $d=10 \mathrm{~mm}$ (reproduced with permission from [136]; published by Wiley-VCH Verlag GmbH \& Co. KGaA, Weinheim, 2015.

\subsection{Magnetic-Repulsion Bistability}

Most vibration energy harvesters use a single degree-of-freedom system [136-142]. The typical bistable structure consisted of a piezoelectric beam converter coupled to permanent magnets [143], as shown in Figure 7a. The magnets were mounted with opposed polarities, so that the resulting magnetic force was repulsive. Under proper conditions, the structure bounced between two stable states in response to external excitation, which significantly improved energy harvesting from wide-spectrum vibrations.

When vibration excitation intensity is insufficient, bistable energy-harvesting systems are not able to realize reciprocating transition oscillations between two wells. To overcome this defect, a combination of bistability and flextensional mechanisms was applied to structural design. Leng et al. conceived an elastic-support model to study the performance of nonlinear piezoelectric vibration energy converters under variable-intensity excitation conditions [144]. The results showed that with the magnet interval and the spring's elastic stiffness unchanged, the elastic-support system had greater power-output performance than a rigid-support system under low-intensity filtered Gaussian noises. Zhou et al. developed a nonlinear flexible bistable energy harvester that comprised a piezoelectric cantilever beam with a tip magnet and a clamped-clamped beam with a midmagnet [145] (Figure 7b). Owing to the variable repulsive magnetic force, the harvester could realize snap-through more easily and create large output voltages. Yang et al. combined bistability and internal resonance effects to broaden the frequency bandwidth of a harvester. The hybrid harvester consisted of a piezoelectric cantilever beam carrying a movable magnet and a fixed magnet [146] (Figure 7c). The spring on the beam allowed the movable magnet to slide along the beam. Compared with bistable energy harvesters with two fixed magnets that had only one branch, the bandwidth of the new design was two times larger. 


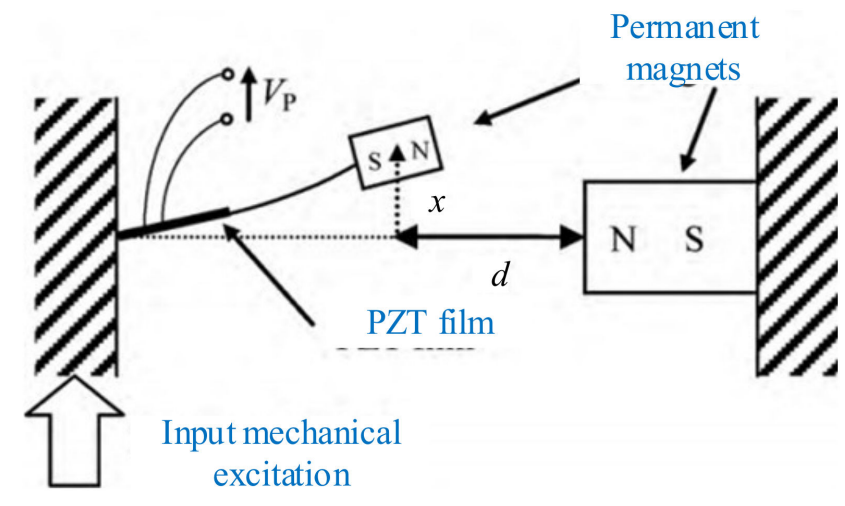

(a)

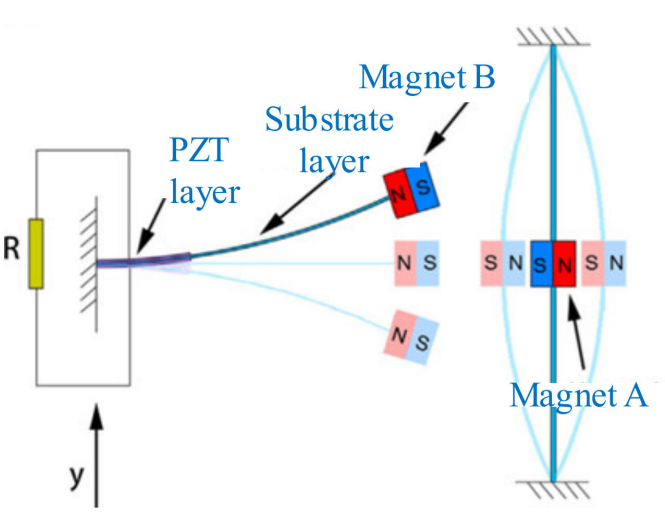

(b)

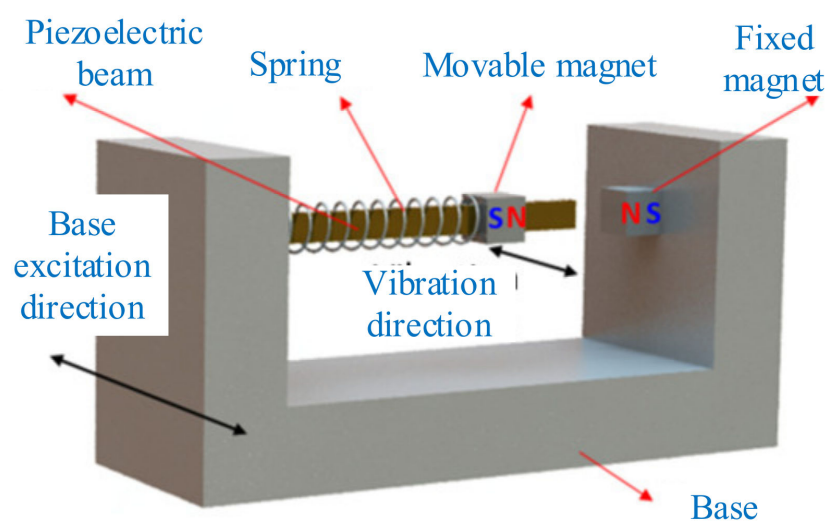

(c)

Figure 7. The bistable harvesters with magnetic repulsion. (a) Bistable system (reproduced with permission from [143]; published by Elsevier B.V., 2010). (b) Nonlinear flexible harvester (reproduced with permission from [145]; published by Elsevier, 2018). (c) Hybrid nonlinear harvester (reproduced with permission from [146]; published by Elsevier, 2016).

Several multi-degree-of-freedom approaches have been proposed to increase the frequency bandwidth [147-151]. Gao et al. developed a bistable dual-piezoelectric-cantilever harvester to achieve optimal broadband energy harvesting under varying-intensity realistic circumstances [152].

\subsection{Magnetic-Attraction Bistability}

The use of magnetic attraction to induce bistability in energy harvesting was studied by some scholars $[153,154]$. Erturk et al. investigated the use of magnetic attraction to induce the bistability of a piezomagnetoelastic beam. The device consisted of a ferromagnetic cantilevered beam with two permanent magnets located symmetrically near the free end, and it was subjected to base excitation [155-157] (Figure 8a). The configuration could generate power an order of magnitude larger compared to commonly employed piezoelastic configurations over a range of frequencies.

Generally, the deep potential wells can bring about the large vibration amplitude. However, the deep wells will create a high barrier. When the harvester is driven by weak excitation, its harvesting efficiency will decrease due to the intrawell motion. Lan et al. developed an improved bistable energy harvester to prompt the ability of harvesting energy [158] (Figure 8b). An additional small magnet was added to the classical bistable harvester, and its magnetic force could pull down the barrier between potential wells. Thus, this device could produce a high output voltage even with weak excitation. 


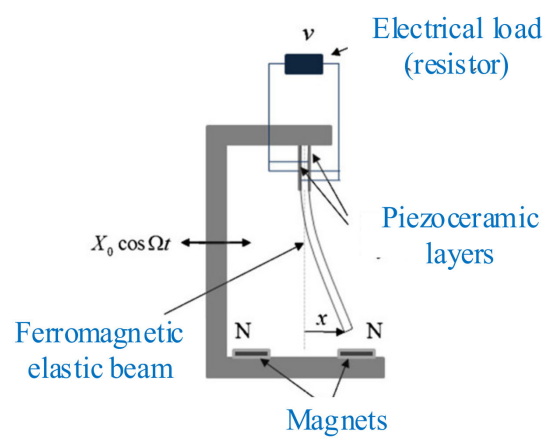

(a)

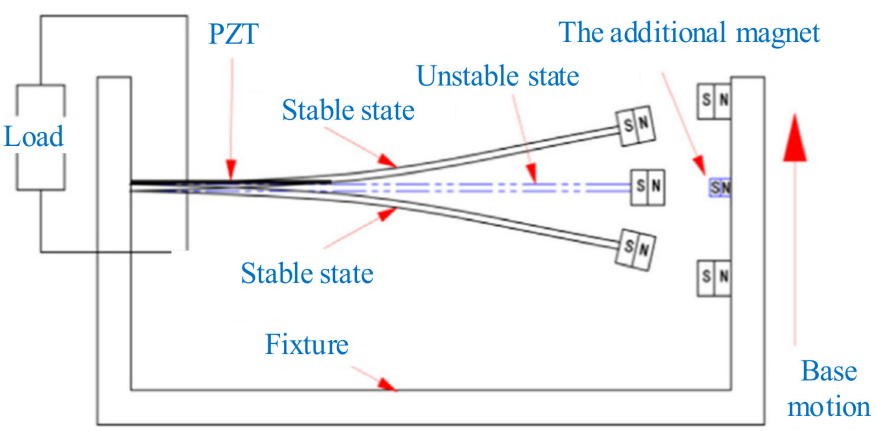

(b)

Figure 8. The bistable harvesters with magnetic attraction. (a) The piezomagnetoelastic energy harvester (reproduced with permission from [157]; published by Elsevier, 2010). (b) An improved bistable energy harvester (reproduced with permission from [158]; published by Elsevier, 2016).

\subsection{Characteristic Analysis of the Bistable Harvesters}

The structural characteristics of some existing bistable-type piezoelectric harvesters are listed in Table 2. It can be found that the bistable structures using magnetic repulsion are widely used compared with magnetic attraction. Magnetic repulsion can reduce the resonance frequency of the structure, which makes it easier to harvest the low-frequency vibration energy. In addition to cantilever, the shape of piezoelectric beams can be arc-shaped, L-shaped, or buckled. Zou et al. proposed a compressive-mode wideband vibration energy harvester that combined the advantages of the bistable oscillator and the flextensional actuator [135]. The flextensional actuator was composed of one PZT layer and two raised metal layers bonded to both sides of the PZT layer. With one flextensional actuator, the instantaneous power was up to $31 \mu \mathrm{W}$, across a load resistance of $390 \mathrm{k} \Omega$ under a base excitation of $0.8 \mathrm{~g}$. Moreover, the number of piezoelectric beams could be one, two, or three.

Table 2. Characteristics of some existing bistable-type piezoelectric harvesters.

\begin{tabular}{|c|c|c|c|c|c|}
\hline Reference & Year & Piezoelectric & Base Layer & Magnetic & Construction Features \\
\hline $\begin{array}{l}\text { Erturk and Inman } \\
\text { [157] }\end{array}$ & 2011 & PZT-5 A & $\begin{array}{l}\text { Tempered blue } \\
\text { steel }\end{array}$ & Attraction & $\begin{array}{l}\text { A ferromagnetic cantilever } \\
\text { with two permanent magnets }\end{array}$ \\
\hline Lan and Qin [158] & 2017 & PZT & $\mathrm{E}=210 \mathrm{GPa}$ & Attraction & $\begin{array}{l}\text { The additional small magnet } \\
\text { reduced the height of barrier } \\
\text { between potential wells }\end{array}$ \\
\hline Lu et al. [154] & 2018 & PZT-5 H & $\begin{array}{l}\text { Carbon fiber } \\
\text { laminate }\end{array}$ & Attraction & $\begin{array}{l}\text { An E-shape broadband } \\
\text { piezoelectric harvester }\end{array}$ \\
\hline Ferrari et al. [143] & 2010 & PZT & Steel & Repulsive & $\begin{array}{l}\text { A piezoelectric converter } \\
\text { coupled to permanent } \\
\text { magnets }\end{array}$ \\
\hline Su et al. [150] & 2013 & PZT-5 H & Aluminum & Repulsive & $\begin{array}{c}\text { Magnet-induced } \\
\text { dual-cantilever }\end{array}$ \\
\hline Zou et al. [135] & 2016 & PZT & $\begin{array}{l}\text { Two raised metal } \\
\text { layers }\end{array}$ & Repulsive & $\begin{array}{l}\text { Bistable and flextensional } \\
\text { mechanisms }\end{array}$ \\
\hline Zou et al. [159] & 2017 & PZT & $65 \mathrm{Mn}$ & Repulsive & $\begin{array}{l}\text { Used two inverted } \\
\text { piezoelectric cantilever beams } \\
\text { for rotational motion }\end{array}$ \\
\hline $\begin{array}{c}\text { Yang and } \\
\text { Towfighian [146] }\end{array}$ & 2017 & $\begin{array}{c}e_{31}=-20 \\
\mathrm{~V} \cdot \mathrm{m} / \mathrm{N}\end{array}$ & $\mathrm{EI}=0.003 \mathrm{~Pa} \cdot \mathrm{m}^{4}$ & Repulsive & $\begin{array}{c}\text { A cantilever with a movable } \\
\text { spring-magnet }\end{array}$ \\
\hline Yao et al. [141] & 2018 & PZT & Brass & Repulsive & $\begin{array}{c}\text { An L-shaped piezoelectric } \\
\text { beam }\end{array}$ \\
\hline Zhang et al. [142] & 2018 & PVDF & $\sim$ & Repulsive & $\begin{array}{l}\text { An arc-shaped piezoelectric } \\
\text { cantilever }\end{array}$ \\
\hline
\end{tabular}


Table 2. Cont

\begin{tabular}{|c|c|c|c|c|c|}
\hline Reference & Year & Piezoelectric & Base Layer & Magnetic & Construction Features \\
\hline Li et al. [132] & 2018 & PZT-5 A & $\mathrm{E}=205 \mathrm{GPa}$ & Repulsive & $\begin{array}{l}\text { A magnet-induced buckled } \\
\text { piezoelectric energy harvester }\end{array}$ \\
\hline Pan et al. [139] & 2019 & PZT-5 H & Steel & Repulsive & $\begin{array}{l}\text { A buckling inverted } \\
\text { piezoelectric beam }\end{array}$ \\
\hline
\end{tabular}

Most of the literature listed studied the excitation direction when perpendicular to the piezoelectric beam. However, Pan et al. proposed an improved inverted beam harvester, and the excitation was applied parallel with the beam in the vertical direction [139]. The additional magnets of this inverted piezoelectric beam could tailor the potential energy, allowing this harvester to undergo snap-through under weak excitation. In addition, Zou et al. presented a magnetically coupled vibration energy harvester using two inverted piezoelectric beams for rotary-motion applications [159]. The high voltages of the first and second resonant points could be obtained at rotating speeds of $420 \mathrm{r} / \mathrm{min}$ and $550 \mathrm{r} / \mathrm{min}$, and the corresponding average output powers were $564 \mu \mathrm{W}$ and $535.3 \mu \mathrm{W}$, respectively.

\section{Multistable Energy Harvesters}

\subsection{Working Mechanism}

Many studies indicated that bistable energy harvesters showed advantages both in frequency bandwidth and average power density. However, due to the barrier in the potential function, the large-amplitude interwell oscillation does not occur all the time, because the intensity of the vibration sources in nature is uncertain. To solve this problem, tristable [160-167], quadstable [168-171] and even pentastable [172-174] configurations were investigated recently. With more potential wells, the potential energy can be distributed more uniformly, and the barriers between the potential wells can be lower, even though the barriers between the potential wells still exist.

The total potential energy of the harvester can be broken up into two components: the elastic potential energy and the magnetic one. The potential energy shapes for quadstable and bistable are plotted in Figure 9a [169]. The potential energy shapes for pentastable and bistable are plotted in Figure 9b [174]. The comparison showed that multistable harvesters had shallower potential wells, and made the distance between the outermost two wells larger. The decrease in depth of the potential well implied that the response of the multistable harvester required quite low energy to realize jumping between the potential wells. Jumping between the nonadjacent wells could create larger amplitudes and generated more power accordingly.

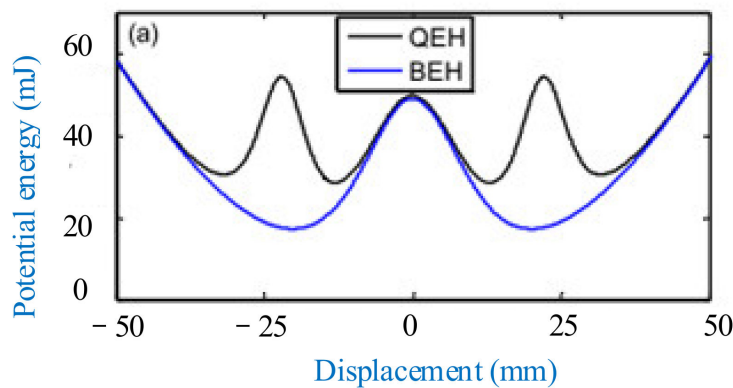

(a)

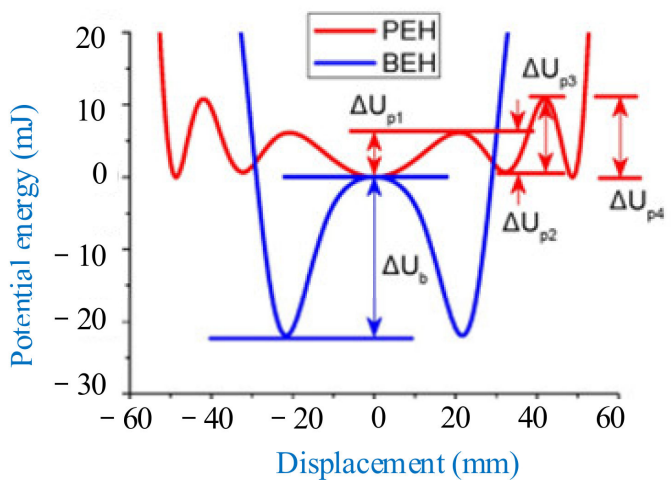

(b)

Figure 9. Potential energy shapes for: (a) Quadstable (QEH) and bistable (BEH) (reproduced with permission from [169]; published by Elsevier, 2016); and (b) pentastable (PEH) and bistable (BEH) (reproduced with permission from [174]; published by Elsevier B.V., 2017). 
Figure 10 shows the bistable and quadstable experimental responses under a frequencysweeping excitation. The quadstable harvesters own a smaller threshold and a wider range of frequencies for occurrence of snap-though than the bistable harvesters. Thus, the multistable energy harvesters show an advantage in scavenging vibration energy under certain conditions.

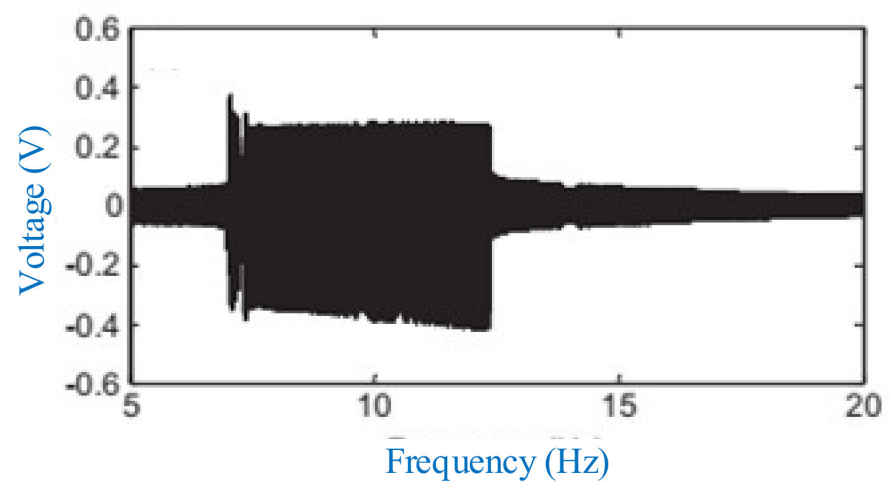

(a)

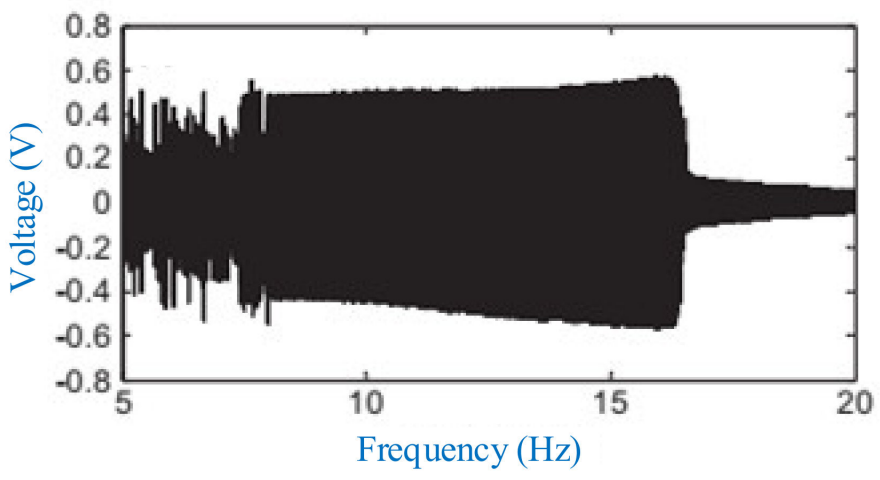

(b)

Figure 10. Tested voltages of energy harvesters under frequency-sweeping excitation. (a) Bistable; (b) quadstable (reproduced with permission from [169]; published by Elsevier, 2016).

\subsection{The Tristable Harvesters}

The common type tristable structure consisted of a piezoelectric beam with two external permanent magnets [175]. Magnet A on the tip of the cantilever beam was the opposite polarity to magnets $\mathrm{B}$ and $\mathrm{C}$, so that the resulting magnetic force was repulsive. This structure had three equilibrium positions from Tables 1-3 in the static state. From the potential energy figures, this harvester had four transitions among monostable, bistable and tristable.

Table 3. Characteristics of some existing multistable-type piezoelectric harvesters.

\begin{tabular}{|c|c|c|c|c|c|}
\hline Reference & Year & Piezoelectric & Base Layer & Multistable & Construction Features \\
\hline Cao et al. [161] & 2015 & PZT-5A & Stainless steel & Tristable & $\begin{array}{l}\text { The performances depended on } \\
\text { the parameters } h, \theta \text {, and } d\end{array}$ \\
\hline Zhu et al. [164] & 2017 & $\begin{array}{c}\mathrm{e}_{31}=23 \times 10^{-10} \\
\mathrm{C} / \mathrm{N}\end{array}$ & $\mathrm{E}=205 \mathrm{GPa}$ & Tristable & $\begin{array}{l}\text { A tristable harvester using } \\
\text { attractive magnets }\end{array}$ \\
\hline Wang et al. [175] & 2019 & PZT & Stainless steel & Tristable & $\begin{array}{l}\text { Improved magnetic-force model } \\
\text { and mathematical model }\end{array}$ \\
\hline Lai et al. [165] & 2019 & MFC & Beryllium bronze & Tristable & $\begin{array}{c}\text { A multistable } \\
\text { piezomagnetoelastic } \\
\text { energy-harvester array }\end{array}$ \\
\hline Zhang et al. [167] & 2020 & PVDF & $\sim$ & Tristable & $\begin{array}{l}\text { A tristable harvester with an arch } \\
\text { composite beam }\end{array}$ \\
\hline Zhou et al. [170] & 2018 & PZT-5 A & $\sim$ & Quadstable & $\begin{array}{c}\text { Shallower and wider potential } \\
\text { wells }\end{array}$ \\
\hline $\begin{array}{l}\text { Abdelhameed et al. } \\
\text { [171] }\end{array}$ & 2019 & K2512U1 & Stainless steel & Quadstable & $\begin{array}{c}\text { A broadband quadstable 2-DOF } \\
\text { energy harvester }\end{array}$ \\
\hline $\begin{array}{c}\text { Kim and Seok } \\
{[172]}\end{array}$ & 2014 & $\mathrm{~d}_{31}=-23 \mathrm{pm} / \mathrm{V}$ & $\mathrm{E}=210 \mathrm{GPa}$ & Pentastable & $\begin{array}{c}\text { Nonlinear magnetic attraction } \\
\text { effect }\end{array}$ \\
\hline Zhou et al. [174] & 2017 & $\begin{array}{c}\mathrm{e}_{31}=23 \times 10^{-10} \\
\mathrm{C} / \mathrm{N}\end{array}$ & $\mathrm{E}=205 \mathrm{GPa}$ & Pentastable & $\begin{array}{l}\text { Nonlinear magnetic force was } \\
\text { generated by a tip magnet and } \\
\text { four external permanent magnets } \\
\text { on an inclined plane }\end{array}$ \\
\hline Wang et al. [173] & 2017 & MFC & Steel & Pentastable & $\begin{array}{l}\text { A piecewise-linear piezoelectric } \\
\text { cantilever with magnetic coupling }\end{array}$ \\
\hline
\end{tabular}


Oumbé Tékam et al. analyzed a tristable energy harvester with fractional order viscoelastic material. The harvester consisted of a piezoelectric cantilever with three magnets placed on the base. The Melnikov theory was used to understand the effects of the physical property of this flexible material [176]. Cao et al. investigated a tristable nonlinear harvester for exploring the performance with different potential well functions under harmonic excitations. The results showed that there was an optimum shallower potential well function that would enhance the effective frequency width under low-frequency excitation [161] (Figure 11a). Lai et al. investigated a nonlinear multistable energy-harvester array combining a tri-stable and a monostable construction [165] (Figure 11b). These harvesters were arranged alternately, and the tip magnets generated a nonlinear repulsive force. By utilizing the interaction between harvesters, this structure had the advantages of higher harvesting efficiency and wider operating bandwidth under low-amplitude $\left(<3 \mathrm{~m} / \mathrm{s}^{2}\right)$ and low-frequency $(<20 \mathrm{~Hz})$ vibrations.

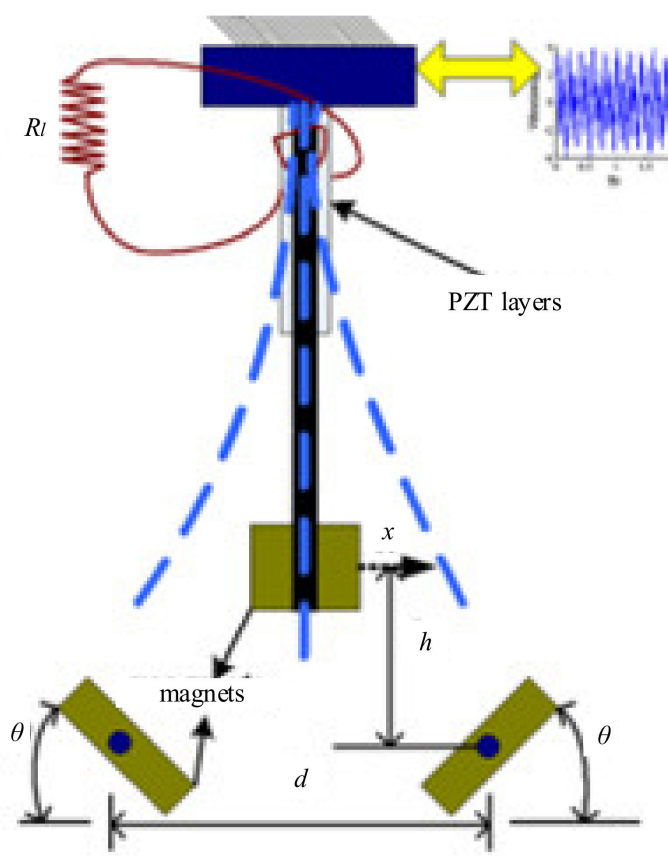

(a)

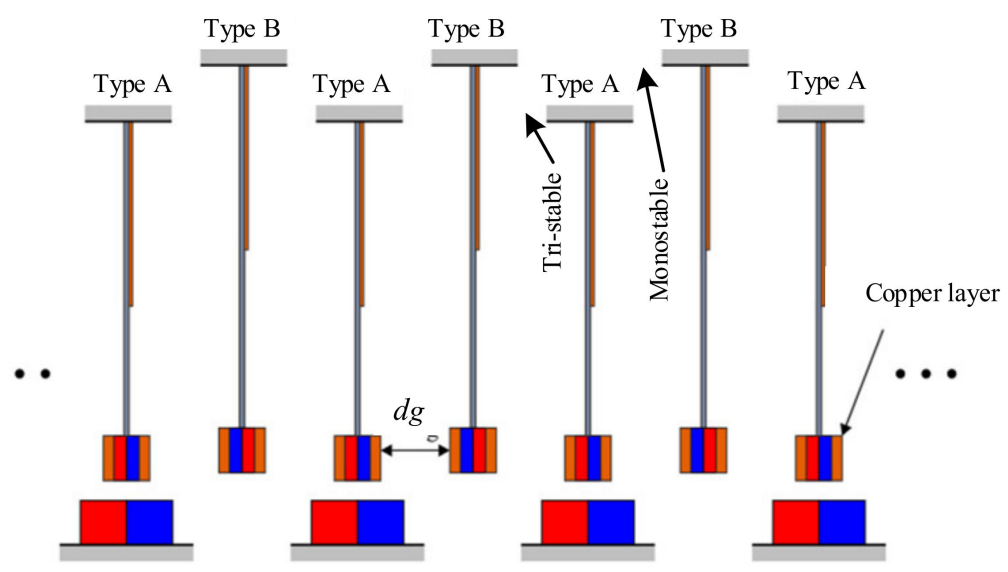

(b)

Figure 11. The tristable harvesters. (a) A tristable nonlinear oscillator (reproduced with permission from [161]; published by AIP, 2015). (b) A nonlinear multistable energy-harvester array (reproduced with permission from [165]; published by Elsevier, 2018).

\subsection{The Quadstable Harvesters}

To improve the energy-conversion ability, a quadstable energy harvester was explored by Zhou et al. Four stable equilibrium positions could be realized in the static state by adjusting the positions and distances between the tip and the fixed magnets [170] (Figure 12a). The research results showed that this harvester exhibited better performances on dynamic response and output voltage than the bistable one.

Two degrees of freedom approaches had been proposed to increase the frequency bandwidth. Abdelhameed et al. developed a 2-DOF quadstable cut-out vibration energy harvester. The tip magnet on the end of the inner beam was repelled by three permanent magnets fixed to the base. This harvester showed a higher figure of merit $(167 \%)$ than that of the bistable one [171] (Figure 12b). In addition to the tri-stable and quad-stable harvesters, pentastable energy harvesting systems also have been proposed. 


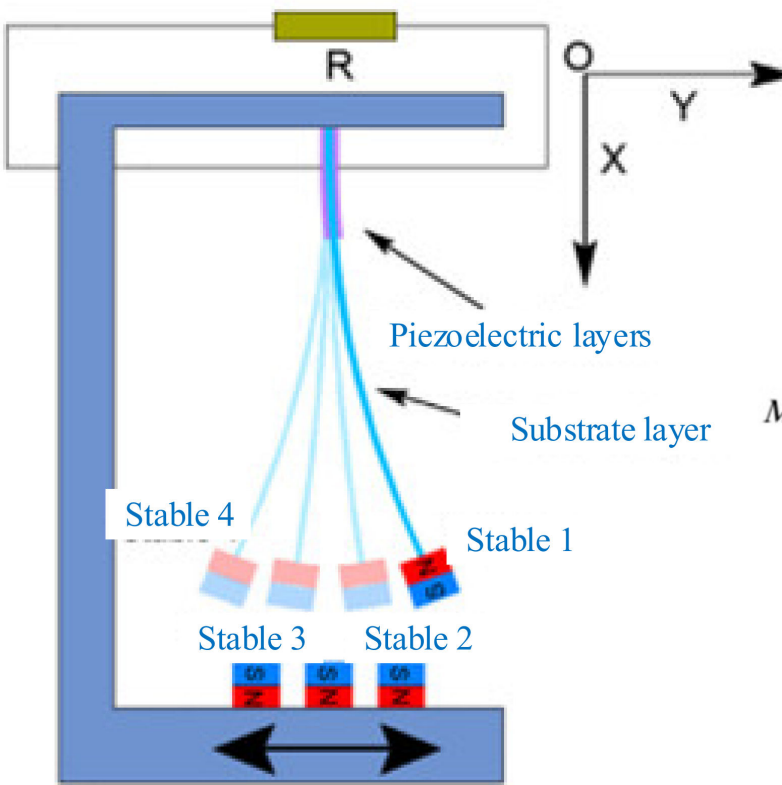

(a)

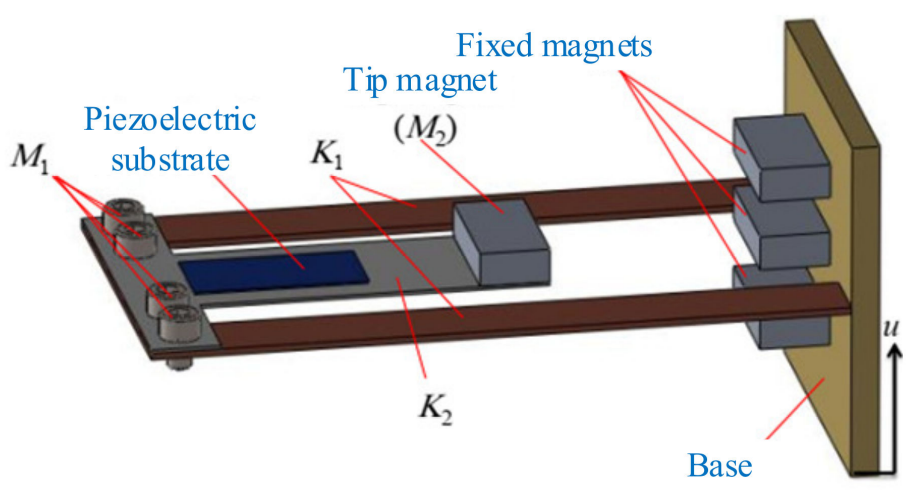

(b)

Figure 12. Some existing quadstable harvesters. (a) A quadstable harvester with one degree of freedom (reproduced with permission from [170]; published by Elsevier, 2018). (b) A quad-stable harvester with two degrees of freedom (2-DOF) (reproduced with permission from [171]; published by MDPI, 2019).

\subsection{Characteristic Analysis of the Multistable Harvesters}

The structural characteristics of some existing multistable-type piezoelectric harvesters are listed in Table 3. Magnetic attraction or magnetic repulsion can induce multistability. The structure could experience monostable, bistable, and tristable states by adjusting the separation and gap distances between magnets $[163,164]$.

In addition to cantilever, the shape of piezoelectric beams can be of a composite shape. Zhang et al. proposed a tristable harvester that comprised a linear-arch composite beam with a tip-magnet attachment and two external magnets. The arched part of the composite beam influenced the response spectrum curve and the potential well depth of this system [167]. In addition to a one degree of freedom structure, a 2-DOF quadstable harvester was studied [171].

\section{Magnetic Plucking Energy Harvesters}

\subsection{Working Mechanism}

The magnetic force can be used as an intermediate driving force to drive the vibration of the piezoelectric beams, which convert the vibration energy into electrical energy [177-189]. It is better to harvest the energy of rotational motion. The magnetic plucking energy harvesters are divided into two groups based on the number of piezoelectric beams used in the harvesters.

For magnetic plucking energy harvesters, the piezoelectric cantilever is the same as that in the nonlinear energy harvester for vibration-to-electricity transduction. However, the difference between them is in how excitations are applied. In the nonlinear energy harvester, a piezoelectric cantilever and magnets as a unit is applied with base excitations. In magnetic plucking, first the piezoelectric cantilever stands still and is excited by magnetic force. The magnet, which follows motions from the external vibrations, interacts with another magnet fixed at the free end of the piezoelectric cantilever, and thus excites the cantilever to vibrate. 
Magnetic plucking is often applied to the strategy of frequency upconversion when energy sources, such as human motions, provide excitations with very low and irregular frequencies. Sensors can be powered by a wave energy harvester using such frequencyupconversion mechanism [57]. A slower-moving inertial mass magnetically plucks a piezoelectric cantilever beam, which converts mechanical energy to electrical energy at a higher frequency. Moreover, piezoelectric energy harvester excited by the magnetic force can be proposed and developed for rotational-mechanism applications. A noncontact magnetic force was applied to excite the piezoelectric cantilever vibration and avoid power frictional loss, as shown in Figure 13 [187].

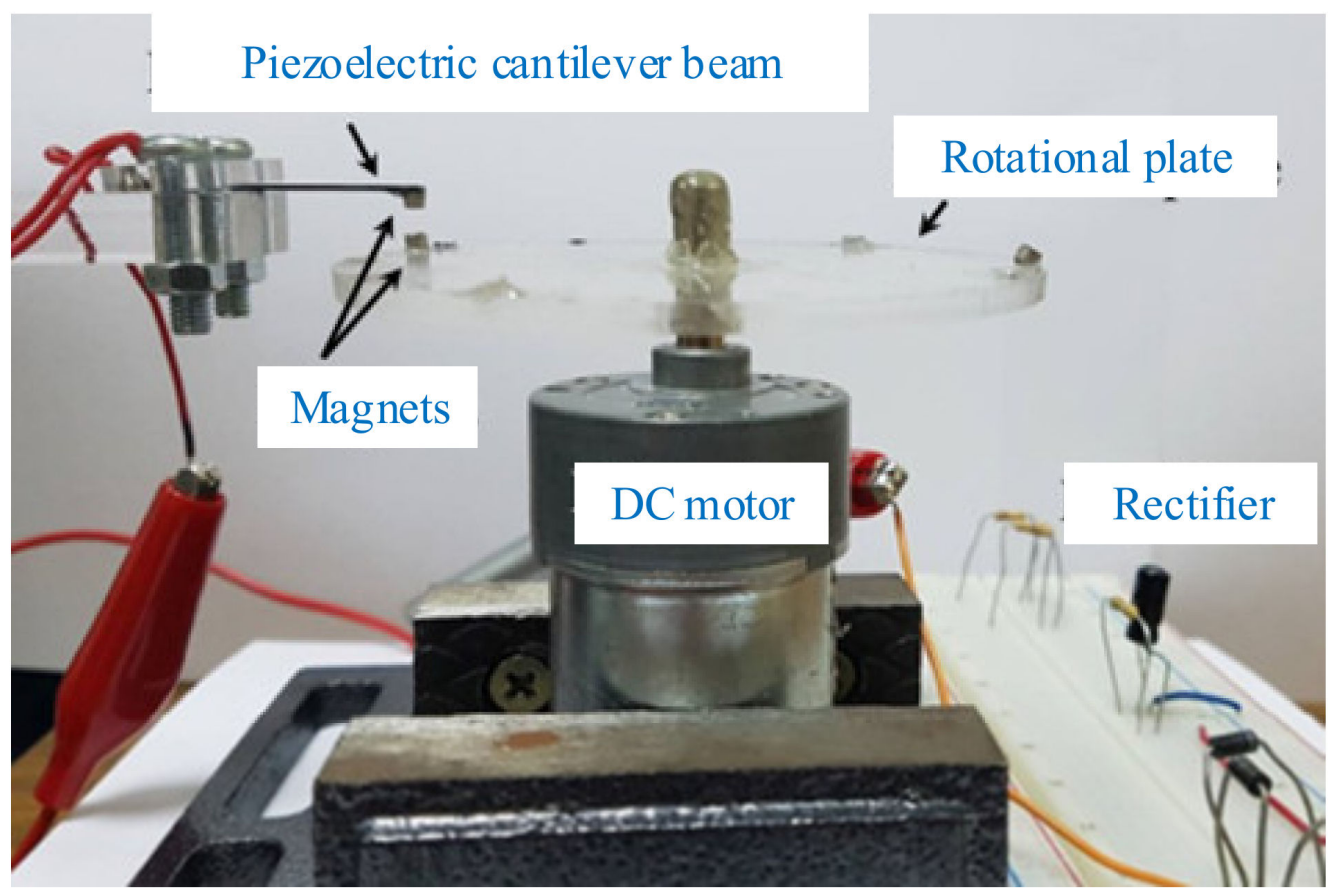

Figure 13. The rotational mechanism (reproduced with permission from [187]; published by Elsevier B.V., 2018).

\subsection{Single Piezoelectric Beam}

The magnets were arranged on the rotating host and the cantilever beam. The angular kinetic energy was transferred to the vibrational energy of the piezoelectric beam via magnetic coupling between the magnets (Figure 14a). Fu and Yeatman investigated the arrangement of repulsion between magnets and the best was chosen for the merits of a high output power [190]. Frequency upconversion was achieved by magnetic plucking, and this harvester had a wide bandwidth at low rotational speeds. More than $20 \mu \mathrm{W}$ of output power could achieve the rotational frequency ranging from 15 to $35 \mathrm{~Hz}$. Xue and Roundy categorized several feasible magnet configurations to achieve magnetic plucking (Figure 14b). The piezoelectric beam could be deflected in or orthogonal to the plane of the rotating magnet motion with magnetic coupling. Results showed that a high-level optimization could be achieved by selection of the number and spacing of beams and magnets for both in-plane and out-of-plane plucking [191]. 


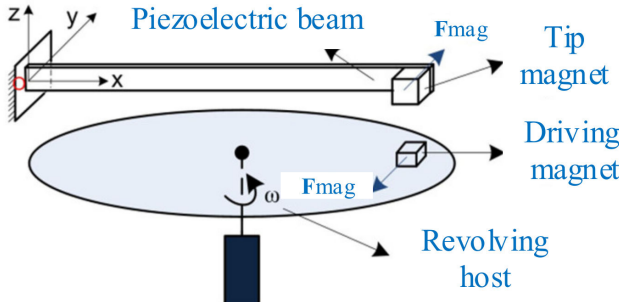

(a)

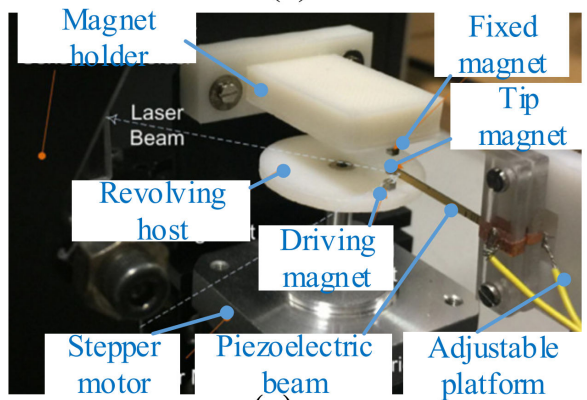

(c)

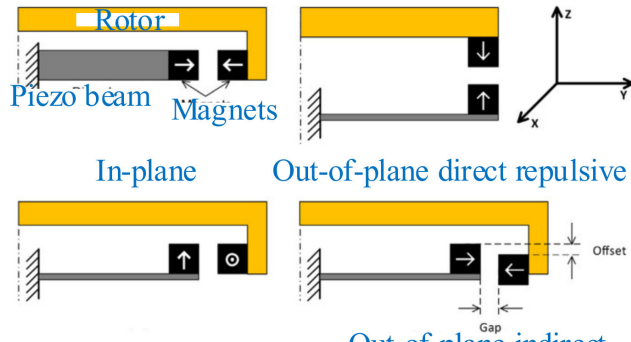

Out-of-plane orthogonal

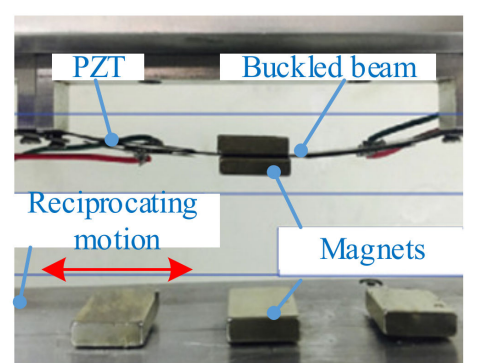

(d)

Figure 14. Magnetic plucking harvesters with a single piezoelectric beam. (a) The rotational energy harvester (reproduced with permission from [190]; published by Elsevier B.V., 2017). (b) Magnetic plucking configurations (reproduced with permission from [191]; published by Elsevier B.V., 2016). (c) A bistable frequency-upconverting harvester (reproduced with permission from [192]; published by Elsevier, 2018). (d) A multistep harvester (reproduced with permission from [193]; published by Elsevier, 2017).

In order to enhance the power-generation capability over a wider bandwidth, Fu and Yeatman investigated a rotational energy harvester using frequency upconversion and bistability (Figure 14c). Another fixed magnet was mounted above the tip magnet at the free end of the beam. The repulsive magnetic force between this magnet and the tip magnet introduced two stable positions for the beam. Results showed that the bistable mechanism allowed the harvester to achieve effective energy harvesting at a low frequency when the harvester operated in the periodic double-well mode [192].

In addition to a piezoelectric cantilever, a clamped beam on both ends driven by a magnetic force can also be used for energy harvesting. Jiang et al. proposed a multistep buckled-beam piezoelectric energy harvester [193] (Figure 14d). The results showed that the magnet array with staggered magnetic poles increased the output voltage of this harvester by $25.0 \%$ compared to the unidirectional magnetic pole arrangement.

\subsection{Multiple Piezoelectric Beams}

Multiple piezoelectric beams driven by magnetic force also were used in some studies for enhancing the overall generated power of the harvester. Ramezanpour et al. proposed a device consisting of a rotating proof mass and eight piezoelectric bimorph beams [194]. The magnet mounted on the rotating pendulum actuated the tips of the eight beams due to magnetic interaction. The results showed that the harvester with a relatively high angular velocity generated more voltage than that with a low angular velocity, and the generated voltage of the attractive case was more than the repulsive one. Adopting a U-shaped bimorph piezoelectric beam, $\mathrm{Hu}$ et al. presented a novel energy harvester that consisted of circularly distributed vibrators, a rotor, and a cylindrical outer casing [195] (Figure 15a). A comprehensive parameter analysis was conducted, including the rotor speed, the thicknesses of the substrate, and the piezoelectric patch. The results indicated that the substrate thickness had the greatest influence on the responses of this harvester. The electric power of this harvester could reach $8.19 \mathrm{~kW}$ under reasonable design. Zou et al. designed a novel magnetically coupled flextensional rotation energy harvester with buckled 
beams [196] (Figure 15b). As the excitation magnets rotated, periodically varying magnetic force was applied to the transducer with magnetic plucking. The component of the magnetic force perpendicular to the transducer was amplified and transmitted to the piezoelectric layer, and the voltage could be produced due to the piezoelectric effect. The results indicated that more excitation magnets and smaller excitation distance could significantly increase the harvested energy. A maximum power of $3.1 \mathrm{~mW}$ could be obtained with one flextensional transducer at a rotating speed of $1000 \mathrm{r} / \mathrm{min}$.

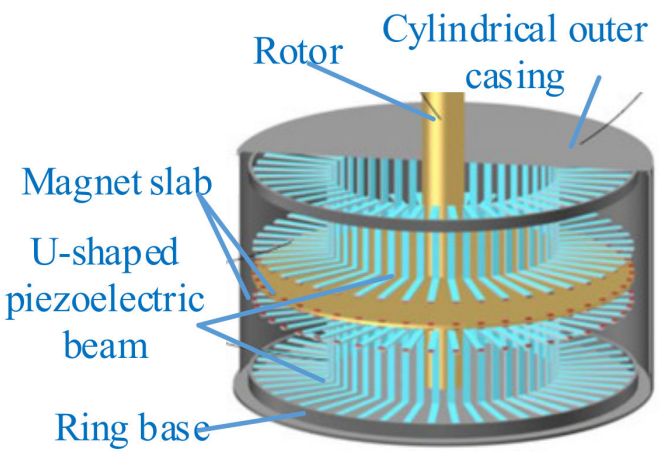

(a)

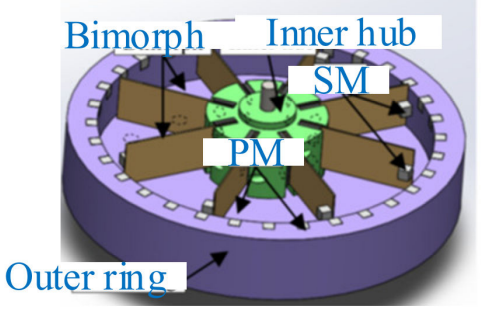

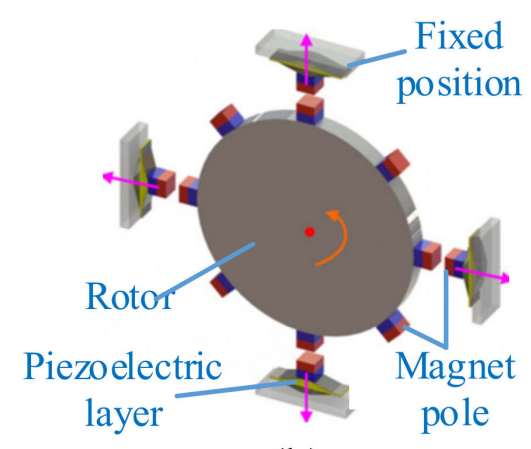

(b)

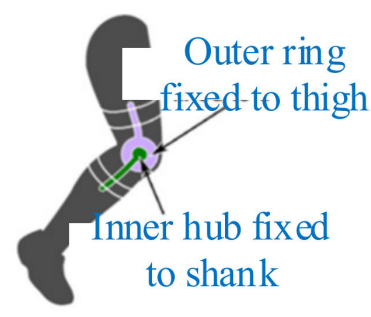

(c)

Figure 15. Magnetic plucking harvesters with multiple piezoelectric beams. (a) A U-shaped piezoelectric coupled harvester (reproduced with permission from [195]; published by Elsevier, 2019). (b) A rotational energy harvester (reproduced with permission from [196]; published by IOP, 2017). (c) A piezoelectric knee-joint harvester (reproduced with permission from [197]; published by IOP, 2016).

In addition, the magnetic-plucking mechanism was also applied to harvest energy from human motion. Kuang et al. introduced a piezoelectric knee-joint energy harvester with frequency upconversion induced by magnetic plucking [197] (Figure 15c). During walking, the thigh and the shank rotated around the knee joint. Then the primary magnet (PM) actuated by the knee-joint motion excited the bimorphs through the secondary magnet (SM) fixed on the beam tip, and this device converted kinetic energy into electric power. An average power output of $5.8 \mathrm{~mW}$ could be acquired by knee-joint motion at a frequency of $0.9 \mathrm{~Hz}$.

\subsection{Characteristic Analysis of the Magnetic-Plucking Harvesters}

Table 4 shows the performances of some existing magnetic-plucking-type piezoelectric harvesters. The magnetic-plucking configurations can be divided into two categories. One is the in-plane layout, where the piezoelectric beam is deflected in the plane of the driving magnet motion. The other is the out-of-plane, where the piezoelectric beam is deflected orthogonal to the plane of the driving magnet motion. The benefit of the out-of-plane 
layout is the possibility of placing multiple piezoelectric beams on a single substrate [191]. In addition, the magnetic force applied to piezoelectric beams is related to the magnetization direction, the position, and the rotation direction of the driving magnet. Furthermore, magnetic-plucking-type piezoelectric harvesters are mainly applied to frequency upconversion, which is suitable for harvesting in low-frequency and high-amplitude environments, such as in human motions. Pozzi designed a wearable knee-joint energy harvester that used magnetic plucking [179]. The rotation of the joint caused the relative rotation between the piezoelectric bimorphs holding permanent magnets and 65 ferromagnetic teeth. Under tests, this harvester generated electrical power of $50 \mathrm{~mW}$ and $70 \mathrm{~mW}$ from walking and running steps, respectively. Yeo et al. proposed a wrist-worn energy harvester using six trapezoidal-shaped cantilever beams with magnetic plucking [189]. The performance of this wrist-worn device was tested under pseudo walking on bench, wrist, and shaking in hand. Compared with a commercial self-powered watch on the same aluminum swing-arm, this harvester could generate power from low-frequency motion. As a whole, proper arrangement of driving magnets and piezoelectric beams will help to improve the performance of the magnetic-plucking piezoelectric energy harvesters.

Table 4. Performances of some existing magnetic-plucking-type piezoelectric harvesters.

\begin{tabular}{|c|c|c|c|c|c|c|c|c|c|c|}
\hline Reference & Year & Piezoelectric & ic ${ }_{\text {Beams }}^{\text {Piezoelectric }}$ & ${ }^{c}$ Magnetic & $\begin{array}{c}\text { Magnet } \\
\text { Configura- } \\
\text { tions }\end{array}$ & $\begin{array}{c}\text { Excitation } \\
\text { Frequency } \\
\text { (Hz) }\end{array}$ & $\begin{array}{l}\text { Resistive } \\
\text { Load }(k \Omega)\end{array}$ & $\begin{array}{l}\text { Beam Size } \mathbf{L} \times \mathbf{B} \\
\times \mathbf{H}\left(\mathrm{mm}^{3}\right)\end{array}$ & $\begin{array}{l}\text { Power } \\
(\mu W)\end{array}$ & Nonlinear Effect \\
\hline $\begin{array}{c}\text { Fu and } \\
\text { Yeatman } \\
\text { [190] }\end{array}$ & 2017 & $\begin{array}{c}\mathrm{e}_{31}= \\
-22.2 \\
\mathrm{~V} \cdot \mathrm{m} / \mathrm{N}\end{array}$ & One & Repulsion & In-plane & $15-35$ & 100 & $26.6 \times 1.5 \times 0.1$ & 20 & $\begin{array}{c}\text { Frequency } \\
\text { upconversion }\end{array}$ \\
\hline $\begin{array}{c}\text { Xue and } \\
\text { Roundy [191] }\end{array}$ & 2017 & $\begin{array}{l}\text { PSI- } \\
\text { 5A4E }\end{array}$ & One & Repulsion & In-plane & 5 & 120 & $26.4 \times 3.2 \times 0.1$ & 3200 & $\begin{array}{c}\text { Frequency } \\
\text { upconversion }\end{array}$ \\
\hline $\begin{array}{l}\text { Jiang et al. } \\
\text { [193] }\end{array}$ & 2017 & PZT-5 H & One & $\begin{array}{l}\text { Attraction } \\
\text { and } \\
\text { Repul- } \\
\text { sion }\end{array}$ & $\begin{array}{l}\text { Out-of- } \\
\text { plane }\end{array}$ & 3.0 & 3300 & $\sim$ & 5.0 & $\begin{array}{l}\text { Multistep } \\
\text { mechanism and } \\
\text { bistability }\end{array}$ \\
\hline $\begin{array}{c}\text { Fu and } \\
\text { Yeatman } \\
\text { [192] }\end{array}$ & 2019 & $\begin{array}{c}\mathrm{e}_{31}= \\
-22.2 \\
\mathrm{~V} \cdot \mathrm{m} / \mathrm{N}\end{array}$ & One & Repulsion & In-plane & 10 & 150 & $33.5 \times 2 \times 0.1$ & 52 & $\begin{array}{l}\text { Bistability and } \\
\text { frequency } \\
\text { upconversion }\end{array}$ \\
\hline $\begin{array}{l}\text { Ramezanpour } \\
\text { et al. [194] }\end{array}$ & 2015 & PZT & Eight & Attraction & $\begin{array}{l}\text { Out-of- } \\
\text { plane }\end{array}$ & 1.67 & 980.5 & $55.01 \times 6.2 \times 0.23$ & About 140 & $\begin{array}{l}\text { Frequency } \\
\text { upconversion }\end{array}$ \\
\hline $\begin{array}{l}\text { Kuang et al. } \\
\text { [197] }\end{array}$ & 2016 & $\mathrm{PZT}$ & Eight & Repulsion & In-plane & 0.9 & 15 & $38.1 \times 12.7 \times 0.38$ & 5800 & $\begin{array}{l}\text { Frequency } \\
\text { upconversion } \\
\text { Magnetically }\end{array}$ \\
\hline $\begin{array}{l}\text { Zou et al. } \\
\text { [196] }\end{array}$ & 2017 & $\mathrm{PZT}$ & $\sim$ & Repulsion & $\begin{array}{l}\text { Out-of- } \\
\text { plane }\end{array}$ & 17 & 240 & $40 \times 10 \times 1$ & 220 (one) & $\begin{array}{l}\text { coupled } \\
\text { flextensional } \\
\text { harvester }\end{array}$ \\
\hline $\begin{array}{l}\text { Yeo et al. } \\
\text { [189] }\end{array}$ & 2018 & PZT & Six & Repulsion & $\begin{array}{l}\text { Out-of- } \\
\text { plane }\end{array}$ & 1 & 18 & $\mathrm{~V}=1.54 \times 10^{-2}$ & 42 & $\begin{array}{c}\text { Frequency } \\
\text { upconversion }\end{array}$ \\
\hline
\end{tabular}

\section{Hybrid Piezoelectric-Electromagnetic Energy Harvesters}

\subsection{Working Mechanism}

The induced electromotive force produced with a magnetic flux through coils varies according to Faraday's law. To improve the energy-conversion efficiency and increase the power density of an energy harvester, the hybrid energy harvester using both piezoelectric and electromagnet conversion mechanisms has received great attention [198-204]. Hybrid piezoelectric-electromagnetic energy harvesters are divided into two groups, according to the number of electromagnetic units.

The hybrid energy harvester contains both piezoelectric and electromagnet conversions. Equation (2) can be expressed in Equations (8) and (9) [100]:

$$
\begin{gathered}
\dot{y}+\frac{1}{R C_{p} \omega_{n}} \dot{y}=\dot{x} \\
\dot{y}+\frac{R}{L \omega_{n}} \dot{y}=\dot{x}
\end{gathered}
$$

where $C p$ is the capacitance of the piezoelectric element, $L$ is the inductance of the harvesting coil, $\omega_{n}$ is the short-circuit nominal frequency, and $y$ is the electric quantity representing 
the induced voltage in piezoelectric harvesters and the induced current in electromagnetic ones. They are measured across an equivalent resistive load $R$.

A typical hybrid energy harvester with the cantilever-beam structure is depicted in Figure 16 [205]. It comprises a piezoelectric cantilever beam with a permanent magnet as the tip mass and a cylindrical induction coil attached to the frame. The piezoelectric cantilever generates electricity by the piezoelectric effect. The magnet is used to tune the resonant frequency and amplify the deformation of the piezoelectric element. Meanwhile, the relative motion between the magnet and coil can induce electric current in the coil. The maximum output power of hybrid energy harvester $(0.913 \mathrm{~mW})$ with matched load resistances is $2.93 \%$ and $142.18 \%$ higher than the stand-alone piezoelectric energy harvester $(0.887 \mathrm{~mW})$ and electromagnetic energy harvester $(0.377 \mathrm{~mW})$, respectively. The operating frequency bandwidth of the hybrid energy harvester is $108 \%$ and $122.7 \%$ times wider than stand-alone piezoelectric and electromagnetic energy harvester, as shown in Figure 17. The hybrid energy harvester has a better computational efficiency.

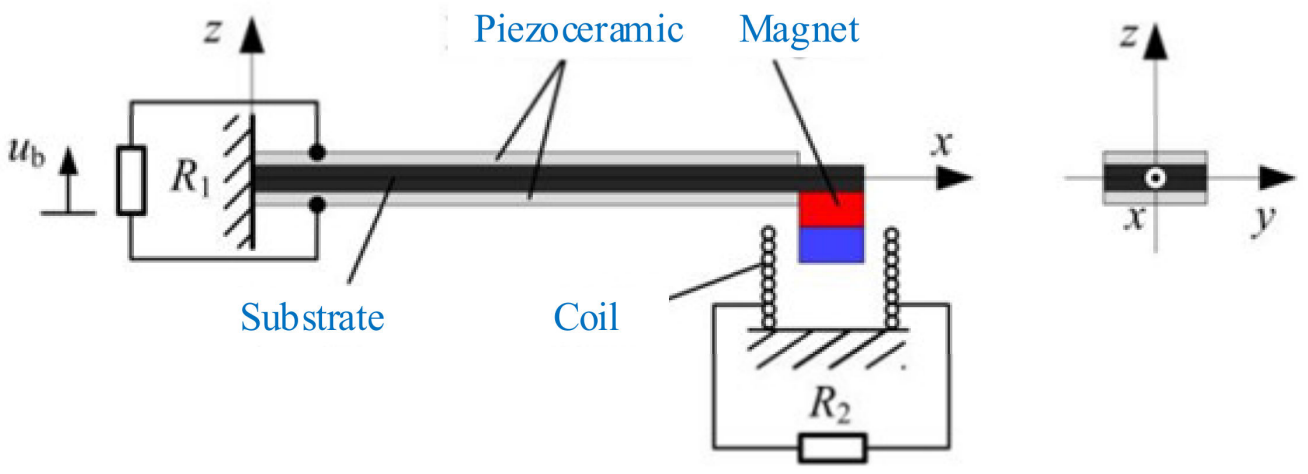

Figure 16. A typical hybrid energy harvester (reproduced with permission from [205]; published by MDPI, 2017).

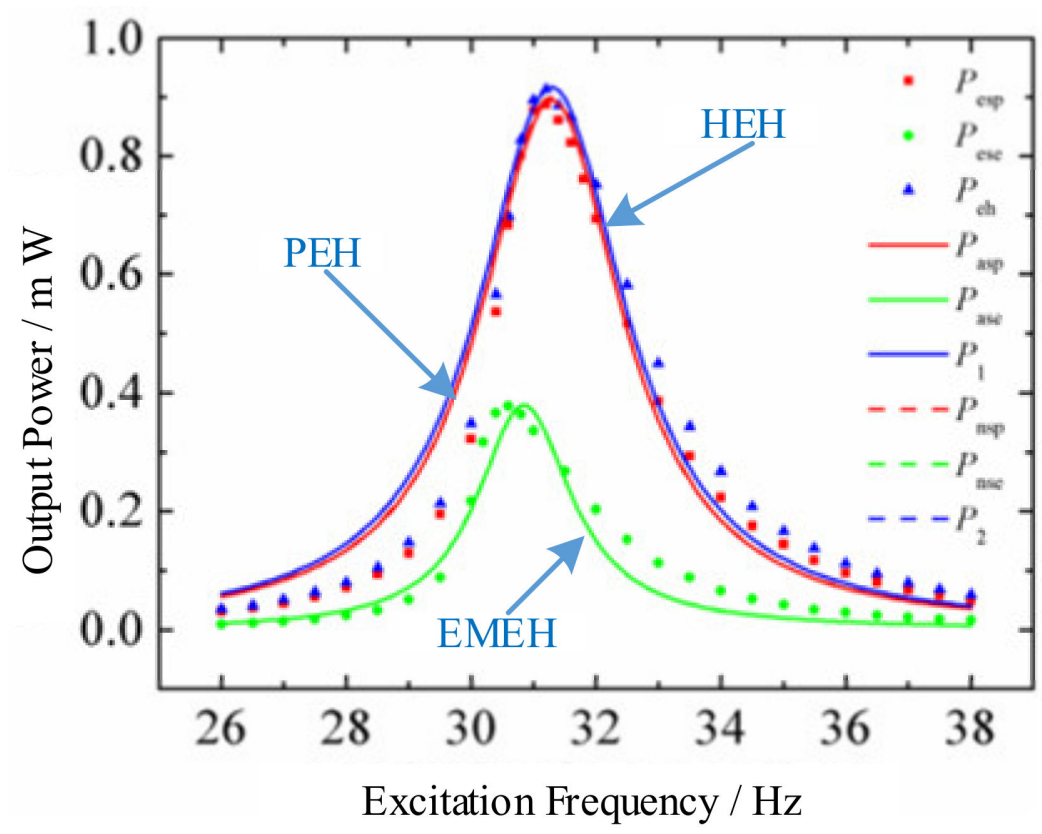

Figure 17. The optimal output power of the stand-alone piezoelectric energy harvester (PEH), standalone electromagnetic energy harvester (EMEH), and hybrid energy harvester (HEH) at different excitation frequencies (reproduced with permission from [205]; published by MDPI, 2017). 


\subsection{One Electromagnetic Unit}

The conventional hybrid harvester consists of a cantilever beam with a bonded piezoelectric patch and a permanent magnet attached to the tip, which oscillates within a coil fixed to the base [205-207]. Yu et al. developed a hybrid microvibration energy harvester that improved total output power and voltage in a low-frequency and small-amplitude vibration environment [208] (Figure 18a). Higher output voltage was obtained by using a piezoelectric cantilever array instead of a traditional single cantilever structure, and a low-power-consumption power-management circuit was designed. Experimental test results showed that the total maximum output power of this hybrid was $40.62 \mu \mathrm{W}$, with an optimal load resistance under the vibration acceleration of $0.2 \mathrm{~g}$.

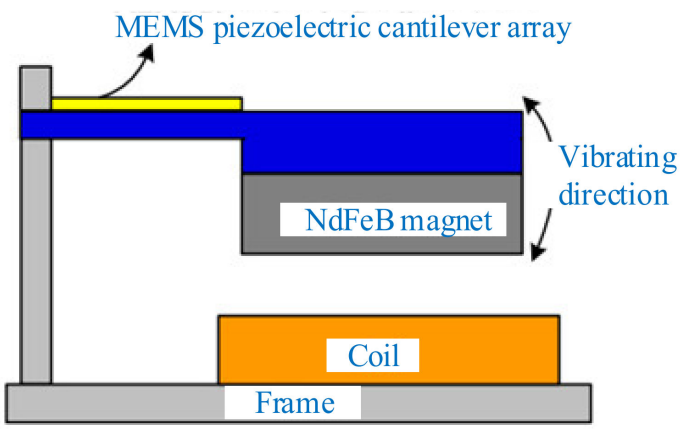

(a)

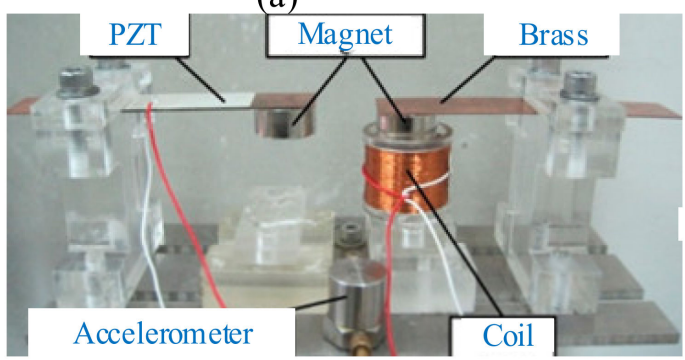

(c)

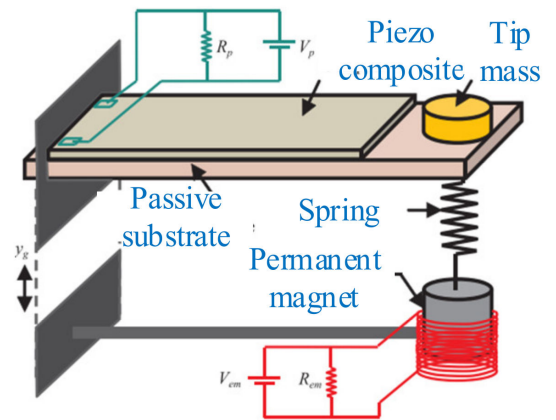

(b)

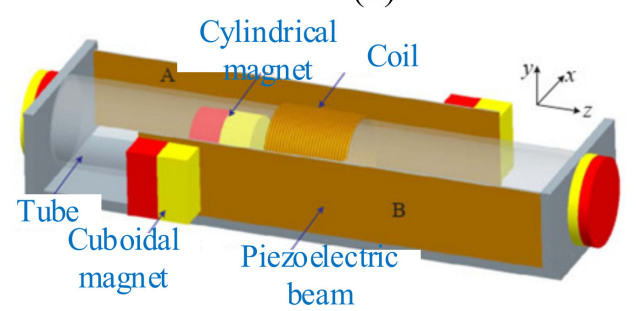

(d)

Figure 18. Representative designs with one electromagnetic unit. (a) A microvibration energy harvester (reproduced with permission from [208]; published by Elsevier B.V., 2014). (b) A 2-DOF system (reproduced with permission from [209]; published by Elsevier, 2017). (c) A multifrequency hybrid harvester (reproduced with permission from [210]; published by MDPI, 2019). (d) A bidirectional harvester (reproduced with permission from [211]; published by Elsevier, 2018).

The drawback of the conventional model is that the power obtained is broad only over a certain region near a single resonant frequency, since it acts as a single degree of freedom system. Rajarathinam and Ali proposed a new model of hybrid energy harvester [209] (Figure 18b) comprising a permanent magnet attached to the free end of a cantilever beam with a linear elastic spring. The studies showed that the harvester operated over a broad range of frequencies as a 2-DOF system, compared to the conventional one. $\mathrm{Xu}$ et al. proposed three types of magnetically coupled hybrid energy harvesters that captured vibrational energy at two discrete frequencies. The superiority of this hybrid energy harvester was demonstrated [210] (Figure 18c). The device contained a typical nonlinear harvester with magnetically coupled dual beams. The hardening and softening nonlinear responses were observed at the first and second resonant frequencies through the frequency upward and downward sweeps, respectively. For this harvester, the optimal peak output powers $(2.96 \mathrm{~mW}$ at $23.6 \mathrm{~Hz}$ and $4.76 \mathrm{~mW}$ at $32.8 \mathrm{~Hz})$ were obtained under $2 \mathrm{~m} / \mathrm{s}^{2}$ excitation acceleration. 
Compared with the harvesters introduced in this part, Fan et al. proposed a novel hybrid harvester that had the capability of extracting energy from bidirectional excitations $(x$ and $z$ ) [211] (Figure 18d). The piezoelectric part operated under the $\mathrm{x}$-directional excitations. The center magnet moved along the tube's axis and triggered the two piezoelectric beams to vibrate with the magnetic coupling in response to the $\mathrm{z}$-directional excitation. Meanwhile, the relative motion between the center magnet and the coil also generated the power output.

\subsection{Multiple Electromagnetic Units}

Multiple electromagnetic units can be added to the hybrid piezoelectric and electromagnet system to improve the efficiency of energy harvesting [212-215]. Li et al. designed a nonlinear hybrid energy harvester that could tune the resonant frequency and improve the harvesting bandwidth at harmonic and random excitation [216]. Two coils were arranged on the upper and lower sides of the double-clamped beam. The resonant frequency and vibration response of this harvester could be tuned by changing the distance and polarity of the movable and fixed magnets. Xia et al. presented a tunable hybrid vibration energy harvester that included operating-frequency tuning and coupling-effect tuning [217] (Figure 19). Two coils were placed opposite to the magnets. The magnets and irons formed a well-designed closed magnetic circuit instead of the isolated magnet model to avoid unstable performance. The first modal frequency bandwidth, ranging from $25.5-62 \mathrm{~Hz}$, was achieved at different relative areas between the magnets and the irons and at $2.78 \mathrm{~mW} \mathrm{av-}$ erage power over the frequency range obtained under a $0.3 \mathrm{~g}$ base acceleration. Benefiting from the proposed technique, the harvester could improve the environmental adaptability.

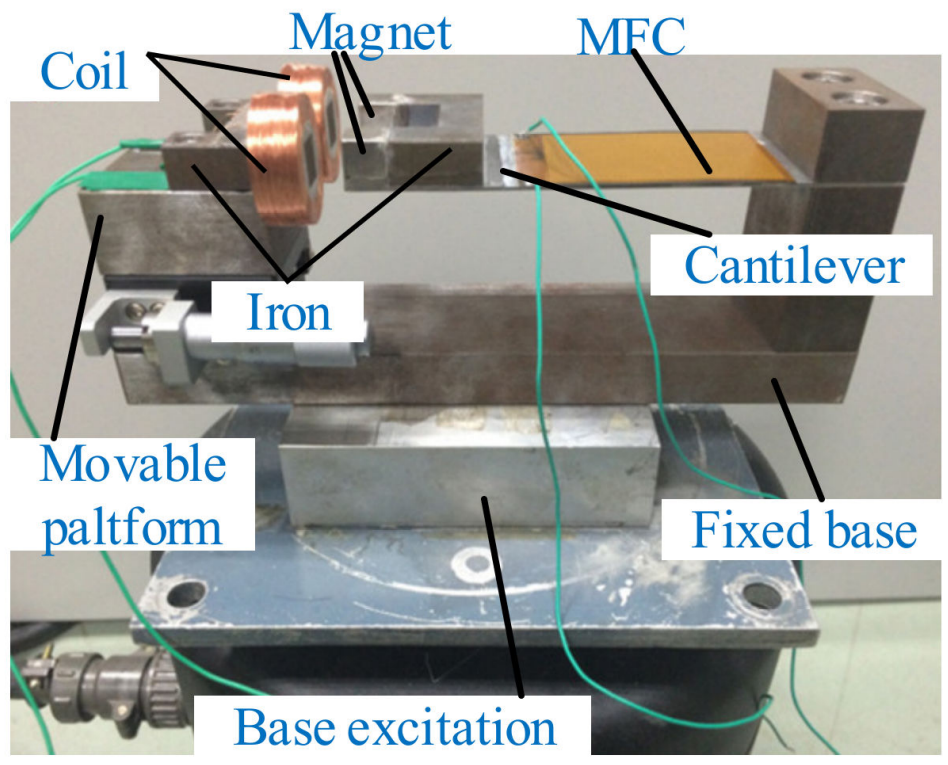

Figure 19. Representative designs with two electromagnetic units (reproduced with permission from [217]; published by Elsevier B.V., 2017).

\subsection{Characteristic Analysis of the Hybrid Harvesters}

In general, a piezoelectric harvester usually generates higher voltage and lower current, but an electromagnetic harvester generates higher current and lower voltage [209]. The hybrid piezoelectric-electromagnetic harvester studied by scholars is expected to produce high voltage and high current simultaneously. Table 5 illustrates the performances of some typical hybrid piezoelectric-electromagnetic harvesters. 
Table 5. Performances of some reported hybrid piezoelectric-electromagnetic harvesters.

\begin{tabular}{|c|c|c|c|c|c|c|c|c|c|c|}
\hline Reference & Year & Piezoelectric & EM Unit & $\begin{array}{l}\text { Acc. } \\
\left(\mathrm{m} / \mathrm{s}^{2}\right)\end{array}$ & $\begin{array}{l}\text { Frequency } \\
\text { (Hz) }\end{array}$ & $\begin{array}{l}\text { PE Load } \\
(\mathrm{k} \Omega)\end{array}$ & $\begin{array}{l}\text { EM Load } \\
\quad(\Omega)\end{array}$ & $\begin{array}{c}\text { Beam Size } \mathrm{L} \times \\
\mathbf{B} \times \mathbf{H}\left(\mathrm{mm}^{3}\right)\end{array}$ & $\begin{array}{l}\text { Power } \\
(\mathrm{mW})\end{array}$ & $\begin{array}{l}\text { Construction } \\
\text { Features }\end{array}$ \\
\hline Yu et al. [208] & 2015 & PZT & one & $0.2 \mathrm{~g}$ & 55.9 & 300 & 400 & $5 \times 2.4 \times 0.05$ & $\begin{array}{c}0.040 .62 \\
\text { (total) }\end{array}$ & MEMS \\
\hline $\begin{array}{l}\text { Salim et al. } \\
\text { [207] }\end{array}$ & 2016 & PZT & one & $0.25 \mathrm{~g}$ & 36 & 300 & 10 & $25 \times 12.7 \times 0.13$ & $\begin{array}{l}0.710 \\
\text { (total) }\end{array}$ & $\begin{array}{l}\text { Ring magnets with a } \\
\text { hanging coil inside }\end{array}$ \\
\hline $\begin{array}{l}\text { Sriramdas } \\
\text { et al. [206] }\end{array}$ & 2018 & PZT & one & $0.5 \mathrm{~g}$ & 22.8 & 286 & 775 & $90 \times 3.5 \times 0.3$ & 1.7 (total) & $\begin{array}{l}\text { A coil oscillating } \\
\text { inside a magnetic } \\
\text { field }\end{array}$ \\
\hline $\begin{array}{l}\text { Rajarathinam } \\
\text { and Ali [209] }\end{array}$ & 2018 & MFC & one & $\sim$ & $\begin{array}{c}2.1 \text { and } \\
14.2\end{array}$ & 50 & 60 & $160 \times 32 \times 1$ & $\sim$ & $\begin{array}{c}\text { Nonlinear and } \\
\text { 2-DOF }\end{array}$ \\
\hline $\begin{array}{c}\text { Fan et al. } \\
\text { [211] }\end{array}$ & 2018 & PZT-5H & one & $1.5 \mathrm{~g}$ & $\sim$ & 180 & 9 & $33 \times 7 \times 0.1$ & $\begin{array}{l}1.23(\mathrm{EM}) \\
\text { and } 0.18 \\
(\mathrm{PE})\end{array}$ & $\begin{array}{c}\text { Frequency } \\
\text { upconversion and } \\
\text { bidirectional }\end{array}$ \\
\hline Xu et al. [210] & 2019 & P-5H & one & 2 & $\begin{array}{c}23.6 \text { and } \\
32.8\end{array}$ & 130 & 2200 & $60 \times 20 \times 0.5$ & $\begin{array}{l}2.96 \text { and } \\
4.76 \text { (total) }\end{array}$ & Multifrequency \\
\hline $\begin{array}{l}\text { Xia et al. } \\
\text { [217] }\end{array}$ & 2017 & MFC & two & $0.3 \mathrm{~g}$ & $\sim$ & $\sim$ & $\sim$ & $\begin{array}{c}\mathrm{V}=712(\mathrm{PE})+ \\
1000(\mathrm{EM})\end{array}$ & 3.32 (total) & $\begin{array}{l}\text { Magnetic tuning } \\
\text { technique }\end{array}$ \\
\hline Li et al. [216] & 2017 & PZT & two & $0.2 \mathrm{~g}$ & $\sim$ & 152.5 & 17.3 & $20 \times 8 \times 3.8$ & 0.46 (total) & $\begin{array}{l}\text { Tuning of the } \\
\text { resonant frequency } \\
\text { and improvment of } \\
\text { the harvesting } \\
\text { bandwidth }\end{array}$ \\
\hline
\end{tabular}

It can be seen in Table 5 that some research findings on hybrid harvester were linear and single-frequency. In this configuration, the harvesters generated the maximum power only under the resonant case. Therefore, some harvesters are designed for harvesting energy from broadband frequency vibrations. For example, the harvesters developed by $\mathrm{Xu}$ et al. [209] and Rajarathinam et al. [210] captured energy with two discrete frequencies. Moreover, some nonlinear technologies, such as frequency upconversion, magnetic tuning, and multistable can be applied to hybrid piezoelectric-electromagnetic harvester to enhance the energy harvesting performance. For example, Yang and Cao presented a novel tristable hybrid vibration energy harvester that was composed of a piezoelectric stack, two ring permanent magnets, and a central inertial mass based on a snap-through spring-mass system [203]. The piezoelectric-stack-generated energy undergoes vibrations. Meanwhile, the relative motions between the ring permanent magnets and the coil generated power due to electromagnetic induction. The hardening-softening spring effect of this tristable harvester produced a large output power, and it was suitable for collecting energy from low- and ultralow-level vibration resources.

\section{Application}

Piezoelectric vibration energy harvesting can also be applied in various areas, including buildings, MEMS, biomechanical and human motions, etc. $[2,72,78,218,219]$. This section focuses on the application of piezoelectric vibration energy harvesting techniques that adopt magnetic force.

One of the applications is powering implantable biomedical devices. Karami and Inman proposed energy harvesters to convert the vibrations from heartbeats to electrical energy for meeting the power requirement of a pacemaker [220]. Both monostable and bistable energy harvesters were designed according to the special signature of heart vibrations. This bistable device could generate power of more than $3 \mu \mathrm{W}$ with the heart rate, which is about three times the power demand of the pacemaker. The batteries and the circuits of the pacemakers are encapsulated in a titanium case. Titanium is a biocompatible material. The sealed casing ensures that there is no contact between the interior of the body and the pacemaker batteries or circuits. Human motions such as arm or leg movements and breathing provide a particular energy source to power wearable and implantable devices [221,222]. Izadgoshasb et al. proposed an efficient piezoelectric harvester that extracted energy from human motions to replace a pacemaker battery [223] (Figure 20a). The use of magnetic coupling with a double-pendulum system was to improve the performance of this harvester. The prototype of this harvester was attached to a human leg 
and arm for practical tests (Figure 20b). The average power harvested from leg and arm motions could reach $86.12 \mu \mathrm{W}$ and $76.25 \mu \mathrm{W}$ in jogging modes, respectively.

In addition, another widespread application is in industry [224-226]. Yuan et al. explored a nonlinear arbitrary-directional broadband piezoelectric vibration energy harvester [227] (Figure 20c). This setup consisted of a 3-DOF parallel mechanism and three sets of polar-opposing permanent magnets. The proposed harvester could achieve effective energy in any direction with a wide bandwidth using the nonlinear magnetic force. The maximum average power of this harvester was $22.3 \mathrm{~mW}$ under an excitation acceleration of $1 \mathrm{~g}$, which is about 2.2 times that of the linear one, and the bandwidth could be up to $5 \mathrm{~Hz}$ with a center frequency of $11 \mathrm{~Hz}$. Yarar et al. investigated a MEMS-based energy-harvesting device [228]. The piezoelectric cantilever of this harvester was covered with aluminum scandiumnitride $(\mathrm{AlScN})$ and driven by permanent magnets. The results showed that the magnetic plucking was more useful to use on a piezoelectric energy harvester for MEMS. The maximum peak power of $15.6 \mu \mathrm{W}$ was obtained across a resistive load of $117210 \Omega$ under an excitation acceleration of $1 \mathrm{~g}$. Vargas and Tinoco presented a piezo-inductive device for energy harvesting [229] (Figure 20d). This configuration generated energy in two parts-the coil moving on the magnetic field, and a piezoelectric transducer. This hybrid harvester obtained higher electrical performance compared with the single mode.

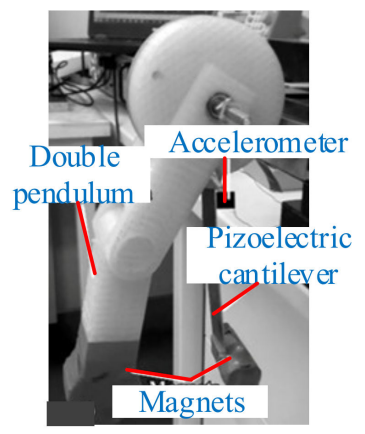

(a)

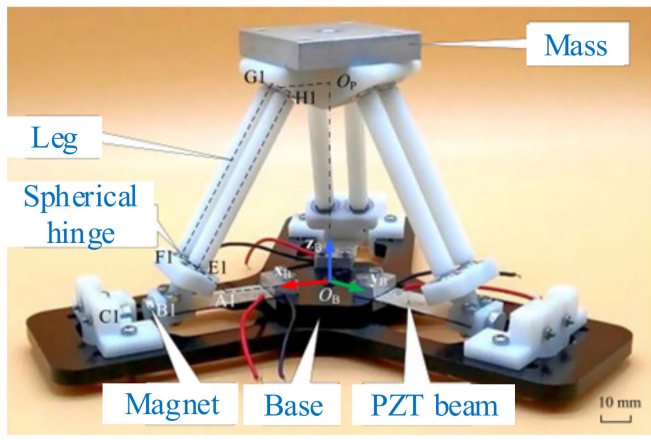

(c)

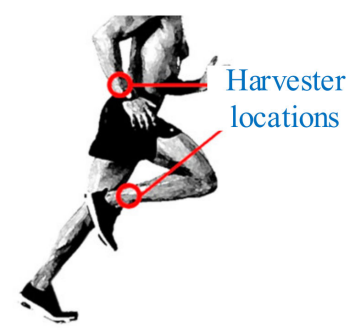

(b)

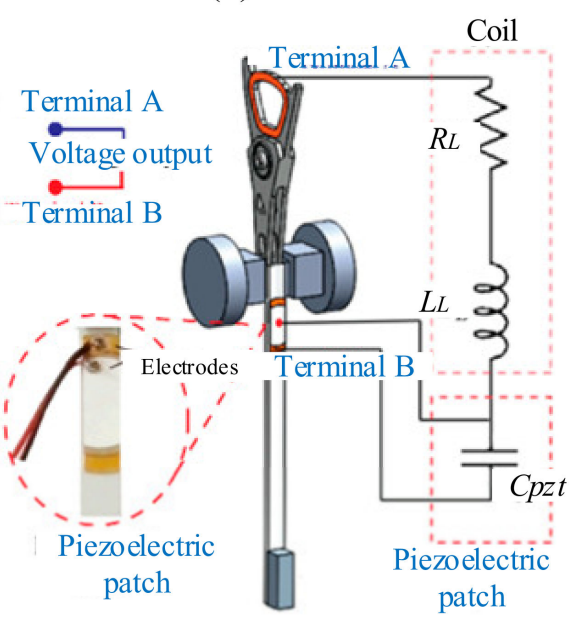

(d)

Figure 20. Representative design in applications. (a) A double-pendulum system (reproduced with permission from [223]; published by Elsevier, 2019). (b) Practical tests on a human leg and arm (reproduced with permission from [223]; published by Elsevier, 2019). (c) An arbitrary-directional harvester (reproduced with permission from [227]; published by IOP, 2019). (d) The hybrid harvester (reproduced with permission from [229]; published by MDPI, 2019).

For piezoelectric materials, PZT is used in many applications. However, its toxic nature may limit its widespread applications. The necessity of alternative-materials research is a challenge for materials scientists. Hybrid, lead-free, polymer-based piezo- 
composites can be efficiently utilized in energy harvesters. However, their piezoelectric performances still require further improvement for widespread use in biomedical devices. Despite the promising potential of implantable energy-harvesting devices, their in vivo application is limited by their cytotoxicity and long-term behavior in host organisms. More coherent and synergistic efforts are needed among material scientists and medical professionals $[35,76,77]$.

\section{Summary and Outlook}

Piezoelectric vibration energy harvesting technology has attracted a lot of attention over the past decade, resulting in a wide variety of papers and applications. Piezoelectric energy harvesting with magnetic coupling promises a more meaningful solution to narrow bandwidth and low energy efficiency. First, this paper presented recent studies of piezoelectric vibration energy harvesting, especially the role of magnetic force in such harvesting. Then, the focus of this review, as summarized below, was on the current advances in effective piezoelectric vibration energy harvesting techniques with magnetic coupling, including monostable, bistable, multistable, magnetic plucking and hybrid piezoelectricelectromagnetic techniques. Finally, applications also were reviewed.

A nonlinear vibration energy harvester can be easily designed by using the magnetic force. Monostable, bistable, or multistable harvesters can be acquired by using magnetic attraction or repulsion. The motion state can be transformed around the monostable state, bistable state, and multistable state under a reasonable arrangement of magnets $[50,230]$. The monostable system exhibits hysteretic resonant behavior due to the nonlinear magnetic effect. When the system's state becomes bistable, the frequency response curve becomes more complicated because of the intrawell, interwell, and chaos motions. The interwell motion is successful due to its remarkable advantages of large-amplitude and broadband characteristics. The magnetic-plucking harvester for rotational energy is simple and easy to realize frequency upconversion, because magnetic force designed as contact-free provides better realization. The number of piezoelectric transduction units, the excitation-magnet arrangement, and the excitation levels all have impacts on energy-harvesting efficiency. The hybrid scheme combining piezoelectric and electromagnetic energy-transduction units have been applied to generate electricity for low-power-requirement electronics. This scheme can significantly increase the harvested energy. It is possible that these methods of adopting magnetic force are very useful for designing efficient vibration-energy harvesters.

This paper provides a meaningful perspective for the design and application of the piezoelectric energy harvester with magnetic coupling. Further research work was carried out for developing new harvesters combining the merits of various methodologies to create a hybrid system for improving the adaptability of the harvester. Moreover, this magneticcoupling technique can be used in a wide range of applications by harvesting various energies from wind, flow, sound, aeroelastic energy, etc. More effective storing circuits and new materials should be developed for achieving better performance in future research.

For piezoelectric vibration energy harvesting, in order to solve the problems of inadequate power density and narrow operating-frequency bandwidth, there have been variety of methods developed, including an array of coupled or uncoupled oscillators across various frequencies, frequency-tuning mechanisms through mechanical or electrical means, and various nonlinear vibratory phenomena. However, magnets are a popular choice to realize nonlinear methods. Monostable, bistable, multistable, frequency upconversion, internal resonance, frequency tuning and other dynamic behaviors can be obtained using magnets. Many nonlinear methods can be integrated to improve the performance of the system using magnets. However, there are disadvantages of the piezoelectric energy harvesters with magnetic coupling. For the hybrid piezoelectric-electromagnetic harvester, fabrication of electromagnetic part on micro- and nanoscales is an area of challenge because of the compact size and significant power rise with the input amplitude, especially with low-frequency vibrations. The magnetic fields can interfere with the use of equipment and may have an impact on the safety of users, especially in medical instruments. In the case of 
pacemakers, a magnetic field is usually avoided due to its effects on device operation. It should be considered whether a device is safe for a living organism.

Nonlinear vibration energy harvesting is still a continuously evolving field. Future research could involve the nonlinear coupling and integration of various nonlinear mechanisms. The ultimate goal for vibration-energy harvesting of maximum power output and broadband response remains an open challenge for ongoing and future research. There is still a gap between the current status and practical applications, especially in biomedical aspects. Another challenge may be in the preparation of piezoelectric scaffolds for use in bone regeneration, sensors for various stimuli, in vivo implantable devices, and e-skin $[3,7,231,232]$. More challenges exist and many problems remain to be solved in the area of piezoelectric vibration energy harvesting. Continued efforts will be necessary to formulate novel solutions to develop effective and practical energy harvesting devices.

Author Contributions: Conceptualization, S.L.; writing-introduction and editing, D.Z.; original draft preparation, J.J.; applications and editing, L.F. All authors have read and agreed to the published version of the manuscript.

Funding: This research was funded by the National Natural Science Foundation of China, grant number NO. 51775123 and NO. 51675111.

Institutional Review Board Statement: The study did not involve humans or animals.

Informed Consent Statement: The study did not involve humans.

Data Availability Statement: The data in the paper is in line with MDPI Research Data Policies.

Conflicts of Interest: The authors declare no conflict of interest.

\section{References}

1. Ahmed, R.; Mir, F.; Banerjee, S. A review on energy harvesting approaches for renewable energies from ambient vibrations and acoustic waves using piezoelectricity. Smart Mater. Struct. 2017, 26, 085031. [CrossRef]

2. Chen, J.; Qiu, Q.; Han, Y.; Lau, D. Piezoelectric materials for sustainable building structures: Fundamentals and applications. Renew. Sustain. Energy Rev. 2019, 101, 14-25. [CrossRef]

3. Mohanty, A.; Parida, S.; Behera, R.K.; Roy, T. Vibration energy harvesting: A review. J. Adv. Dielectr. 2019, 9, 1930001. [CrossRef]

4. Wei, C.; Jing, X. A comprehensive review on vibration energy harvesting: Modelling and realization. Renew. Sustain. Energy Rev. 2017, 74, 1-18. [CrossRef]

5. Elahi, H.; Eugeni, M.; Gaudenzi, P. A review on mechanisms for piezoelectric-based energy harvesters. Energies 2018, 11, 1850. [CrossRef]

6. Liu, S.; Cheng, Q.; Zhao, D.; Feng, L. Theoretical modeling and analysis of two-degree-of-freedom piezoelectric energy harvester with stopper. Sens. Actuators A Phys. 2016, 245, 97-105. [CrossRef]

7. Szarka, G.D.; Stark, B.H.; Burrow, S.G. Review of power conditioning for kinetic energy harvesting systems. IEEE Trans. Power Electron. 2012, 27, 803-815. [CrossRef]

8. Zhao, D.; Wang, X.; Cheng, Y.; Liu, S.; Wu, Y.; Chai, L.; Liu, Y.; Cheng, Q. Analysis of single-degree-of-freedom piezoelectric energy harvester with stopper by incremental harmonic balance method. Mater. Res. Express 2018, 5, 055502. [CrossRef]

9. Fei, W.; Hansen, O. Electrostatic energy harvesting device with out-of-the-plane gap closing scheme. Sens. Actuators A Phys. 2014, 211, 131-137.

10. Naito, Y.; Uenishi, K. Electrostatic MEMS vibration energy harvesters inside of tire treads. Sensors 2019, 19, 890. [CrossRef] [PubMed]

11. Suzuki, Y.; Miki, D.; Edamoto, M.; Honzumi, M. A MEMS electret generator with electrostatic levitation for vibration-driven energy-harvesting applications. J. Micromech. Microeng. 2010, 20, 104002. [CrossRef]

12. Tan, Y.; Dong, Y.; Wang, X. Review of MEMS electromagnetic vibration energy harvester. J. Microelectromech. Syst. 2017, 26, 1-16. [CrossRef]

13. Costanzo, L.; Vitelli, M. Tuning techniques for piezoelectric and electromagnetic vibration energy harvesters. Energies 2020, 13, 527. [CrossRef]

14. Foong, F.M.; Thein, C.K.; Ooi, B.L.; Yurchenko, D. Increased power output of an electromagnetic vibration energy harvester through anti-phase resonance. Mech. Syst. Signal Process. 2019, 116, 129-145. [CrossRef]

15. Chandrasekaran, S.; Bowen, C.; Roscow, J.; Zhang, Y.; Dang, D.K.; Kim, E.J.; Misra, R.D.K.; Deng, L.; Chung, J.S.; Hur, S.H. Micro-scale to nano-scale generators for energy harvesting: Self powered piezoelectric, triboelectric and hybrid devices. Phys. Rep. 2019, 792, 1-33. [CrossRef] 
16. Maiti, S.; Karan, S.K.; Kim, J.K.; Khatua, B.B. Nature driven bio-piezoelectric/triboelectric nanogenerator as next-generation green energy harvester for smart and pollution free society. Adv. Energy Mater. 2019, 9, 1803027. [CrossRef]

17. Zheng, Q.; Shi, B.; Li, Z.; Wang, Z.L. Recent progress on piezoelectric and triboelectric energy harvesters in biomedical systems. Adv. Sci. 2017, 4, 1700029. [CrossRef] [PubMed]

18. Dong, L.; Closson, A.B.; Jin, C.; Trase, I.; Chen, Z.; Zhang, J.X.J. Vibration-energy-harvesting system: Transduction mechanisms, frequency tuning techniques, and biomechanical applications. Adv. Mater. Technol. 2019, 4, 1900177. [CrossRef]

19. Tang, L.; Yang, Y.; Soh, C.K. Toward broadband vibration-based energy harvesting. J. Intell. Mater. Syst. Struct. 2010, $21,1867-1897$. [CrossRef]

20. Roundy, S.; Wright, P.K. A piezoelectric vibration based generator for wireless electronics. Smart Mater. Struct. 2004, 13, 1131-1142. [CrossRef]

21. Li, X.; Upadrashta, D.; Yu, K.; Yang, Y. Analytical modeling and validation of multi-mode piezoelectric energy harvester. Mech. Syst. Signal Process. 2019, 124, 613-631. [CrossRef]

22. Sun, R.; Li, Q.; Yao, J.; Scarpa, F.; Rossiter, J. Tunable, multi-modal, and multi-directional vibration energy harvester based on three-dimensional architected metastructures. Appl. Energy 2020, 264, 114615. [CrossRef]

23. Dechant, E.; Fedulov, F.; Fetisov, L.; Shamonin, M. Bandwidth widening of piezoelectric cantilever beam arrays by mass-tip tuning for low-frequency vibration energy harvesting. Appl. Sci. 2017, 7, 1324. [CrossRef]

24. Ibrahim, S.W.; Ali, W.G. A review on frequency tuning methods for piezoelectric energy harvesting systems. J. Renew. Sustain. Energy 2012, 4, 062703. [CrossRef]

25. Shi, G.; Yang, Y.; Chen, J.; Peng, Y.; Xia, H.; Xia, Y. A broadband piezoelectric energy harvester with movable mass for frequency active self-tuning. Smart Mater. Struct. 2020, 29, 055023. [CrossRef]

26. Abedini, A.; Wang, F. Energy harvesting of a frequency up-conversion piezoelectric harvester with controlled impact. Eur. Phys. J. Spec. Top. 2019, 228, 1459-1474. [CrossRef]

27. Chen, S.; Ma, L.; Chen, T.; Liu, H.; Sun, L.; Wang, J. Modeling and verification of a piezoelectric frequency-up-conversion energy harvesting system. Microsyst. Technol. 2016, 23, 2459-2466. [CrossRef]

28. Huang, M.; Hou, C.; Li, Y.; Liu, H.; Wang, F.; Chen, T.; Yang, Z.; Tang, G.; Sun, L. A low-frequency mems piezoelectric energy harvesting system based on frequency up-conversion mechanism. Micromachines 2019, 10, 639. [CrossRef]

29. Zizys, D.; Gaidys, R.; Ostasevicius, V.; Narijauskaite, B. Vibro-shock dynamics analysis of a tandem low frequency resonator-high frequency piezoelectric energy harvester. Sensors 2017, 17, 970. [CrossRef]

30. Jiang, H.; Kiziroglou, M.E.; Yates, D.C.; Yeatman, E.M. A motion-powered piezoelectric pulse generator for wireless sensing via FM transmission. IEEE Internet Things J. 2015, 2, 5-13. [CrossRef]

31. Tang, Q.; Li, X. Two-stage wideband energy harvester driven by multimode coupled vibration. IEEE ASME Trans. Mechatron. 2015, 20, 115-121. [CrossRef]

32. Ibrahima, D.S.; Muthalif, A.G.A.; Saleh, T. A piezoelectric based energy harvester with magnetic interactions: Modelling and simulation. Adv. Mater. Res. 2015, 1115, 549-554. [CrossRef]

33. Upadrashta, D.; Yang, Y.; Tang, L. Material strength consideration in the design optimization of nonlinear energy harvester. J. Intell. Mater. Syst. Struct. 2014, 26, 1980-1994. [CrossRef]

34. Wen, S.; Wu, Z.; Xu, Q. Design of a novel two-directional piezoelectric energy harvester with permanent magnets and multistage force amplifier. IEEE Trans. Ultrason. Ferroelectr. Freq. Control 2020, 67, 840-849. [CrossRef] [PubMed]

35. Surmenev, R.A.; Orlova, T.; Chernozem, R.V.; Ivanova, A.A.; Bartasyte, A.; Mathur, S.; Surmeneva, M.A. Hybrid lead-free polymer-based nanocomposites with improved piezoelectric response for biomedical energy-harvesting applications: A review. Nano Energy 2019, 62, 475-506. [CrossRef]

36. Ibrahim, D.S.; Muthalif, A.G.A.; Nordin, N.H.D.; Saleh, T. Comparative study of conventional and magnetically coupled piezoelectric energy harvester to optimize output voltage and bandwidth. Microsyst. Technol. 2017, 23, 2663-2674. [CrossRef]

37. Xu, J.; Tang, J. Linear stiffness compensation using magnetic effect to improve electro-mechanical coupling for piezoelectric energy harvesting. Sens. Actuators A Phys. 2015, 235, 80-94. [CrossRef]

38. He, Q.; Jiang, T. Complementary multi-mode low-frequency vibration energy harvesting with chiral piezoelectric structure. Appl. Phys. Lett. 2017, 110, 213901. [CrossRef]

39. Fan, K.; Yu, B.; Zhu, Y.; Liu, Z.; Wang, L. Scavenging energy from the motion of human lower limbs via a piezoelectric energy harvester. Int. J. Mod. Phys. B 2017, 31, 1741011. [CrossRef]

40. He, Q.; Li, K.; Han, R.; Wang, J.; Li, X. Sub-g weak-vibration-triggered high-efficiency energy harvesting for event identification. J. Micromech. Microeng. 2018, 28, 075018. [CrossRef]

41. Li, K.; He, Q.; Wang, J.; Zhou, Z.; Li, X. Wearable energy harvesters generating electricity from low-frequency human limb movement. Microsyst. Nanoeng. 2018, 4, 24. [CrossRef]

42. Nezami, S.; Jung, H.; Lee, S. Design of a disk-swing driven piezoelectric energy harvester for slow rotary system application. Smart Mater. Struct. 2019, 28, 074001. [CrossRef]

43. Panthongsy, P.; Isarakorn, D.; Janphuang, P.; Hamamoto, K. Fabrication and evaluation of energy harvesting floor using piezoelectric frequency up-converting mechanism. Sens. Actuators A Phys. 2018, 279, 321-330. [CrossRef]

44. Ibrahim, A.; Towfighian, S.; Younis, M.I. Dynamics of transition regime in bistable vibration energy harvesters. J. Vib. Acoust. 2017, 139, 051008. [CrossRef] 
45. Lan, C.; Tang, L.; Qin, W.; Xiong, L. Magnetically coupled dual-beam energy harvester: Benefit and trade-off. J. Intell. Mater. Syst. Struct. 2017, 29, 1216-1235. [CrossRef]

46. Harne, R.L.; Wang, K.W. A review of the recent research on vibration energy harvesting via bistable systems. Smart Mater. Struct. 2013, 22, 023001. [CrossRef]

47. Kim, J.; Dorin, P.; Wang, K.W. Vibration energy harvesting enhancement exploiting magnetically coupled bistable and linear harvesters. Smart Mater. Struct. 2020, 29, 065006. [CrossRef]

48. Pellegrini, S.P.; Tolou, N.; Schenk, M.; Herder, J.L. Bistable vibration energy harvesters: A review. J. Intell. Mater. Syst. Struct. 2012, 24, 1303-1312. [CrossRef]

49. Avvari, P.V.; Tang, L.; Yang, Y.; Soh, C.K. Enhancement of piezoelectric energy harvesting with multi-stable nonlinear vibraons. Proc. SPIE 2013, 8688, 86882H-1.

50. Jung, J.; Kim, P.; Lee, J.-I.; Seok, J. Nonlinear dynamic and energetic characteristics of piezoelectric energy harvester with two rotatable external magnets. Int. J. Mech. Sci. 2015, 92, 206-222. [CrossRef]

51. Leng, Y.; Tan, D.; Liu, J.; Zhang, Y.; Fan, S. Magnetic force analysis and performance of a tri-stable piezoelectric energy harvester under random excitation. J. Sound Vib. 2017, 406, 146-160. [CrossRef]

52. Panyamn, M.; Daqaq, M.F. Characterizing the effective bandwidth of tri-stableenergy harvesters. J. Sound Vib. 2017, 386, 336-358. [CrossRef]

53. Sun, X.; Wang, F.; Xu, J. Nonlinear Piezoelectric structure for ultralow-frequency band vibration energy harvesting with magnetic interaction. Int. J. Precis. Eng. Manuf. Green Technol. 2019, 6, 671-679. [CrossRef]

54. Bouhedma, S.; Zheng, Y.; Lange, F.; Hohlfeld, D. Magnetic frequency tuning of a multimodal vibration energy harvester. Sensors 2019, 19, 1149. [CrossRef] [PubMed]

55. Yang, C.L.; Chen, K.W.; Chen, C.D. Model and characterization of a press-button-type piezoelectric energy harvester. IEEE ASME Trans. Mechatron. 2019, 24, 132-143. [CrossRef]

56. Cottone, F.; Vocca, H.; Gammaitoni, L. Nonlinear energy harvesting. Phys. Rev. Lett. 2009, 102, 080601. [CrossRef] [PubMed]

57. Tang, L.; Yang, Y.; Soh, C.-K. Improving functionality of vibration energy harvesters using magnets. J. Intell. Mater. Syst. Struct. 2012, 23, 1433-1449. [CrossRef]

58. Zhou, S.; Cao, J.; Inman, D.J.; Lin, J.; Liu, S.; Wang, Z. Broadband tristable energy harvester: Modeling and experiment verification. Appl. Energy 2014, 133, 33-39. [CrossRef]

59. Wang, C.; Zhang, Q.; Wang, W. Wideband quin-stable energy harvesting via combined nonlinearity. AIP Adv. 2017, 7, 045314. [CrossRef]

60. Rezaei-Hosseinabadi, N.; Tabesh, A.; Dehghani, R. A topology and design optimization method for wideband piezoelectric wind energy harvesters. IEEE Trans. Ind. Electron. 2016, 63, 2165-2173. [CrossRef]

61. Avirovik, D.; Kishore, R.; Bressers, S.; Inman, D.J.; Priya, S. Miniature contactless piezoelectric wind turbine. Integr. Ferroelectr. 2015, 159, 1-13. [CrossRef]

62. Bouzelata, Y.; Kurt, E.; Uzun, Y.; Chenni, R. Mitigation of high harmonicity and design of a battery charger for a new piezoelectric wind energy harvester. Sens. Actuators A Phys. 2018, 273, 72-83. [CrossRef]

63. Yang, C.H.; Song, Y.; Jhun, J.; Hwang, W.S.; Hong, S.D.; Woo, S.B.; Sung, T.H.; Jeong, S.W.; Yoo, H.H. A high efficient piezoelectric windmill using magnetic force for low wind speed in wireless sensor networks. J. Korean Phys. Soc. 2018, 73, 1889-1894. [CrossRef]

64. Bo, L.D.; Gardonio, P. Energy harvesting with electromagnetic and piezoelectric seismic transducers: Unified theory and experimental validation. J. Sound Vib. 2018, 433, 385-424.

65. Iqbal, M.; Khan, F.U. Hybrid vibration and wind energy harvesting using combined piezoelectric and electromagnetic conversion for bridge health monitoring applications. Energy Convers. Manag. 2018, 172, 611-618. [CrossRef]

66. Zhao, D.; Liu, S.; Xu, Q.; Sun, W.; Wang, T.; Cheng, Q. Theoretical modeling and analysis of a 2-degree-of-freedom hybrid piezoelectric-electromagnetic vibration energy harvester with a driven beam. J. Intell. Mater. Syst. Struct. 2018, 29, 2465-2476. [CrossRef]

67. Cheng, R.; Zhang, C.; Zhang, C.; Chen, W. Magnetically controllable piezotronic responses in a composite semiconductor fiber with multiferroic coupling effects. Phys. Status Solidi A 2019, 217, 1900621. [CrossRef]

68. Fetisov, L.Y.; Urdin, D.B.; Ekonomov, N.; Chashin, D.V.; Zhang, J.; Srinivasan, G.; Fetisov, Y.K. Nonlinear magnetoelectric effects at high magnetic field amplitudes in composite multiferroics. J. Phys. D Appl. Phys. 2018, 51, 1. [CrossRef]

69. Gupta, R.; Tomar, M.; Kumar, A.; Gupta, V. Performance of magnetoelectric PZT/Ni multiferroic system for energy harvesting application. Smart Mater. Struct. 2017, 26, 035002. [CrossRef]

70. Onuta, T.-D.; Wang, Y.; Long, C.J.; Takeuchi, I. Energy harvesting properties of all-thin-film multiferroic cantilevers. Appl. Phys. Lett. 2011, 99, 203506. [CrossRef]

71. Wu, H.; Tatarenko, A.; Bichurin, M.I.; Wang, Y. A multiferroic module for biomechanical energy harvesting. Nano Energy 2021, 83, 105777. [CrossRef]

72. Ali, F.; Raza, W.; Li, X.; Gul, H.; Kim, K.-H. Piezoelectric energy harvesters for biomedical applications. Nano Energy 2019, 57, 879-902. [CrossRef]

73. Chorsi, M.T.; Curry, E.J.; Chorsi, H.T.; Das, R.; Baroody, J.; Purohit, P.K.; Ilies, H.; Nguyen, T.D. Piezoelectric biomaterials for sensors and actuators. Adv. Mater. 2019, 31, e1802084. [CrossRef] [PubMed] 
74. Dabrowska, A.; Greszta, A. Analysis of the possibility of using energy harvesters to power wearable electronics in clothing. Adv. Mater. Sci. Eng. 2019, 2019, 9057293. [CrossRef]

75. Feng, H.; Zhao, C.; Tan, P.; Liu, R.; Chen, X.; Li, Z. Nanogenerator for biomedical applications. Adv. Healthc. Mater. 2018, 7, e1701298. [CrossRef] [PubMed]

76. Salim, M.; Salim, D.; Chandran, D.; Aljibori, H.S.; Kherbeet, A.S. Review of nano piezoelectric devices in biomedicine applications. J. Intell. Mater. Syst. Struct. 2018, 29, 2105-2121. [CrossRef]

77. Shi, B.; Li, Z.; Fan, Y. Implantable energy-harvesting devices. Adv. Mater. 2018, 30, 1801511. [CrossRef] [PubMed]

78. Kanno, I. Piezoelectric MEMS: Ferroelectric thin films for MEMS applications. Jpn. J. Appl. Phys. 2018, 57, 040101. [CrossRef]

79. Saadon, S.; Sidek, O. A review of vibration-based MEMS piezoelectric energy harvesters. Energy Convers. Manag. 2011, 52, 500-504. [CrossRef]

80. Tian, W.; Ling, Z.; Yu, W.; Shi, J. A review of MEMS scale piezoelectric energy harvester. Appl. Sci. 2018, 8, 645. [CrossRef]

81. Todaro, M.T.; Guido, F.; Mastronardi, V.; Desmaele, D.; Epifani, G.; Algieri, L.; de Vittorio, M. Piezoelectric MEMS vibrational energy harvesters: Advances and outlook. Microelectron. Eng. 2017, 183, 23-36. [CrossRef]

82. Toshiyoshi, H.; Ju, S.; Honma, H.; Ji, C.H.; Fujita, H. MEMS vibrational energy harvesters. Sci. Technol. Adv. Mater. 2019, 20, 124-143. [CrossRef]

83. Khan, A.A.; Mahmud, A.; Ban, D. Evolution from single to hybrid nanogenerator: A contemporary review onmultimode energy harvesting for self-powered electronics. IEEE Trans. Nanotechnol. 2019, 18, 21-36. [CrossRef]

84. Park, J.Y.; Salauddin, M.; Rasel, M.S. Nanogenerator for scavenging low frequency vibrations. J. Micromech. Microeng. 2019, 29, 053001. [CrossRef]

85. Roji, M.A.M.; Jiji, G.; Raj, T.A.B. A retrospect on the role of piezoelectric nanogenerators in the development of the green world. RSC Adv. 2017, 7, 33642-33670. [CrossRef]

86. Kaczmarek, H.; Krlikowski, B.; Klimiec, E.; Chylińska, M.; Bajer, D. Advances in the study of piezoelectric polymers. Russ. Chem. Rev. 2019, 88, 1. [CrossRef]

87. Iqbal, A.; Mohd-Yasin, F. Reactive sputtering of aluminum nitride (002) thin films for piezoelectric applications: A review. Sensors 2018, 18, 1797. [CrossRef] [PubMed]

88. Jing, Q.; Kar-Narayan, S. Nanostructured polymer-based piezoelectric and triboelectric materials and devices for energy harvesting applications. J. Phys. D Appl. Phys. 2018, 51, 303001. [CrossRef]

89. Kou, J.; Liu, Y.; Zhu, Y.; Zhai, J. Progress in piezotronics of transition-metal dichalcogenides. J. Phys. D Appl. Phys. 2018, 51, 493002. [CrossRef]

90. Ramadan, K.S.; Sameoto, D.; Evoy, S. A review of piezoelectric polymers as functional materials for electromechanical transducers. Smart Mater. Struct. 2014, 23, 033001. [CrossRef]

91. Choi, J.; Jung, I.; Kang, C.-Y. A brief review of sound energy harvesting. Nano Energy 2019, 56, 169-183. [CrossRef]

92. Abdelkefi, A. Aeroelastic energy harvesting: A review. Int. J. Eng. Sci. 2016, 100, 112-135. [CrossRef]

93. Gong, Y.; Yang, Z.; Shan, X.; Sun, Y.; Xie, T.; Zi, Y. Capturing flow energy from ocean and wind. Energies 2019, 12, 2184. [CrossRef]

94. Zhao, L.; Yang, Y. Toward small-scale wind energy harvesting: Design, enhancement, performance comparison, and applicability. Shock. Vib. 2017, 2017, 3585972. [CrossRef]

95. Abdelmoula, H.; Zimmerman, S.; Abdelkefi, A. Accurate modeling, comparative analysis, and performance enhancement of broadband piezoelectric energy harvesters with single and dual magnetic forces. Int. J. Non-linear Mech. 2017, 95, 355-363. [CrossRef]

96. Dhote, S.; Yang, Z.; Behdinan, K.; Zu, J. Enhanced broadband multi-mode compliant orthoplanar spring piezoelectric vibration energy harvester using magnetic force. Int. J. Mech. Sci. 2018, 135, 63-71. [CrossRef]

97. Rui, X.; Li, Y.; Liu, Y.; Zheng, X.; Zeng, Z. Experimental study and parameter optimization of a magnetic coupled piezoelectric energy harvester. Appl. Sci. 2018, 8, 2609. [CrossRef]

98. Upadrashta, D.; Yang, Y. Finite element modeling of nonlinear piezoelectric energy harvesters with magnetic interaction. Smart Mater. Struct. 2015, 24, 045042. [CrossRef]

99. Daqaq, M.F. On intentional introduction of stiffness nonlinearities for energy harvesting under white Gaussian excitations. Nonlinear Dynam. 2012, 69, 1063-1079. [CrossRef]

100. Daqaq, M.F.; Masana, R.; Erturk, A.; Quinn, D.D. On the role of nonlinearities in vibratory energy harvesting: A critical review and discussion. Appl. Mech. Rev. 2014, 66, 13. [CrossRef]

101. Cai, W.; Harne, R.L. Vibration energy harvesters with optimized geometry, design, and nonlinearity for robust direct current power delivery. Smart Mater. Struct. 2019, 28, 075040. [CrossRef]

102. Maeguchi, T.; Masuda, A.; Katsumura, H.; Kagata, H.; Okumura, H. Band widening of piezoelectric vibration energy harvesters by utilizing mechanical stoppers and magnets. J. Phys. Conf. Ser. 2015, 660, 012099. [CrossRef]

103. Yang, W.; Towfighian, S. A parametric resonator with low threshold excitation for vibration energy harvesting. J. Sound Vib. 2019, 446, 129-143. [CrossRef]

104. Yang, Z.; Tang, L.; Xie, M.; Sun, S.; Li, W.; Aw, K. Soft magneto-sensitive elastomer and polyvinylidene fluoride polymer based nonlinear piezoelectric energy harvesting: Design, modelling and experiment. Smart Mater. Struct. 2019, 28, 015031. [CrossRef]

105. Deng, W.; Wang, Y. Input-dependent performance study of a nonlinear piezoelectric energy harvester. J. Intell. Mater. Syst. Struct. 2016, 28, 619-626. [CrossRef] 
106. Krishnasamy, M.; Upadrashta, D.; Yang, Y.; Lenka, T.R. Distributed parameter modelling of cutout 2-DOF cantilevered piezomagneto-elast. J. Microelectromech. Syst. 2018, 26, 1160-1170. [CrossRef]

107. Krishnasamy, M.; Lenka, T.R. Analytical model with two degree of freedom of piezo-magneto-elastic energy harvester for low-frequency wide bandwidth applications. Micro Nano Lett. 2018, 13, 857-861. [CrossRef]

108. Wu, H.; Tang, L.; Yang, Y.; Soh, C.K. Development of a broadband nonlinear two-degree-of-freedom piezoelectric energy harvester. J. Intell. Mater. Syst. Struct. 2014, 25, 1875-1889. [CrossRef]

109. Upadrashta, D.; Yang, Y. Nonlinear piezomagnetoelastic harvester array for broadband energy harvesting. J. Appl. Phys. 2016, 120, 054504. [CrossRef]

110. Chen, L.; Jiang, W. A piezoelectric energy harvester based on internal resonance. Acta Mech. Sin. 2015, 31, 223-228. [CrossRef]

111. Xiong, L.; Tang, L.; Mace, B.R. Internal resonance with commensurability induced by an auxiliary oscillator for broadband energy harvesting. Appl. Phys. Lett. 2016, 108, 203901. [CrossRef]

112. Chen, L.-Q.; Jiang, W.-A.; Panyam, M.; Daqaq, M.F. A Broadband Internally Resonant Vibratory Energy Harvester. J. Vib. Acoust. 2016, 138, 061007. [CrossRef]

113. Xiong, L.; Tang, L.; Mace, B.R. A comprehensive study of 2:1 internal-resonance-based piezoelectric vibration energy harvesting. Nonlinear Dynam. 2017, 91, 1817-1834. [CrossRef]

114. Yang, W.; Towfighian, S. Internal resonance and low frequency vibration energy harvesting. Smart Mater. Struct. 2017, $26,095008$. [CrossRef]

115. Ren, Z.; Zhao, H.; Liu, C.; Qian, L.; Zhang, S.; Zhao, J. Study the influence of magnetic force on nonlinear energyharvesting performance. AIP Adv. 2019, 9, 105107. [CrossRef]

116. Abdelkefi, A.; Barsallo, N. Nonlinear analysis and power improvement of broadband low-frequency piezomagnetoelastic energy harvesters. Nonlinear Dyn. 2015, 83, 41-56. [CrossRef]

117. Alcala-Jimenez, L.R.; Jensen, T.P.; Lei, A.; Thomsen, E.V. Increased mechanical robustness of piezoelectric magnetoelastic vibrational energy harvesters. Microelectron. Eng. 2019, 207, 19-26. [CrossRef]

118. Alomari, A.; Batra, A.; Tan, A.; Schamschula, M. Enhanced piezoelectric energy harvester performance using magnetic force and thermal energy. Integr. Ferroelectr. 2016, 176, 291-302. [CrossRef]

119. Firoozy, P.; Khadem, S.E.; Pourkiaee, S.M. Broadband energy harvesting using nonlinear vibrations of a magnetopiezoelastic cantilever beam. Int. J. Eng. Sci. 2017, 111, 113-133. [CrossRef]

120. Zhang, G.; Gao, S.; Liu, H.; Niu, S. A low frequency piezoelectric energy harvester with trapezoidal cantilever beam: Theory and experiment. Microsyst. Technol. 2016, 23, 3457-3466. [CrossRef]

121. Zhang, X.; Zuo, M.; Tan, H.; Wu, Z.; Lai, Z.; Fan, H. Dynamics analysis of multi-field coupled piezoelectric energy harvester under random excitation. IOP Conf. Ser. Mater. Sci. Eng. 2019, 531, 012038. [CrossRef]

122. Stanton, S.C.; McGehee, C.C.; Mann, B.P. Reversible hysteresis for broadband magnetopiezoelastic energy harvesting. Appl. Phys. Lett. 2010, 95, 174103. [CrossRef]

123. Shih, H.-A.; Su, W.-J. Theoretical analysis and experimental study of a nonlinear U-shaped bi-directional piezoelectric energy harvester. Smart Mater. Struct. 2019, 28, 015017. [CrossRef]

124. Fan, K.; Tan, Q.; Liu, H.; Zhang, Y.; Cai, M. Improved energy harvesting from low-frequency small vibrations through a monostable piezoelectric energy harvester. Mech. Syst. Signal Process. 2019, 117, 594-608. [CrossRef]

125. Fan, K.; Tan, Q.; Zhang, Y.; Liu, S.; Cai, M.; Zhu, Y. A monostable piezoelectric energy harvester for broadband low-level excitations. Appl. Phys. Lett. 2018, 112, 123901. [CrossRef]

126. Zhang, Z.; Kan, J.; Wang, S.; Wang, H.; Yang, C.; Chen, S. Performance dependence on initial free-end levitation of a magnetically levitated piezoelectric vibration energy harvester with a composite cantilever beam. IEEE Access 2017, 5, 27563-27572. [CrossRef]

127. Singh, K.A.; Kumar, R.; Weber, R.J. A broadband bistable piezoelectric energy harvester with nonlinear high-power extraction. IEEE Trans. Power Electron. 2015, 30, 6763-6774. [CrossRef]

128. Singh, K.A.; Pathak, M.; Weber, R.J.; Kumar, R. A self-propelled mechanism to increase range of bistable operation of a piezoelectric cantilever-based vibration energy harvester. IEEE Trans. Ultrason. Ferroelectr. Freq. Control 2018, 65, 2184-2194. [CrossRef]

129. Cao, J.; Zhou, S.; Inman, D.J.; Chen, Y. Chaos in the fractionally damped broadband piezoelectric energy generator. Nonlinear Dyn. 2014, 80, 1705-1719. [CrossRef]

130. Cao, J.; Zhou, S.; Inman, D.J.; Lin, J. Nonlinear dynamic characteristics of variable inclination magnetically coupled piezoelectric energy harvesters. J. Vib. Acoust. 2015, 137, 021015. [CrossRef]

131. Cheng, C.; Chen, Z.; Xiong, Y.; Shi, H.; Yang, Y. A high-efficiency, self-powered nonlinear interface circuit for bi-stable rotating piezoelectric vibration energy harvesting with nonlinear magnetic force. Int. J. Appl. Electrom. 2016, 51, 235-248. [CrossRef]

132. Li, H.; Qin, W.; Deng, W. Coherence resonance of a magnet-induced buckled piezoelectric energy harvester under stochastic parametric excitation. J. Intell. Mater. Syst. Struct. 2017, 29, 1620-1631. [CrossRef]

133. Zhang, Y.; Jin, Y. Stochastic dynamics of a piezoelectric energy harvester with correlated colored noises from rotational environment. Nonlinear Dyn. 2019, 98, 501-515. [CrossRef]

134. Zou, H.-X.; Zhang, W.-M.; Li, W.-B.; Wei, K.-X.; Hu, K.-M.; Peng, Z.-K.; Meng, G. Magnetically coupled flextensional transducer for wideband vibration energy harvesting: Design, modeling and experiments. J. Sound Vib. 2018, 416, 55-79. [CrossRef]

135. Zou, H.-X.; Zhang, W.-M.; Wei, K.-X.; Li, W.-B.; Peng, Z.-K.; Meng, G. A compressive-mode wideband vibration energy harvester using a combination of bistable and flextensional mechanisms. J. Appl. Mech. 2016, 83, 121005. [CrossRef] 
136. Kumar, T.; Kumar, R.; Chauhan, V.S.; Twiefel, J. Finite-element analysis of a varying-width bistable piezoelectric energy harvester. Energy Technol. (Weinh.) 2015, 3, 1243-1249. [CrossRef]

137. Chen, Z.; Guo, B.; Cheng, C.; Shi, H.; Yang, Y. Chaotic dynamics-based analysis of broadband piezoelectric vibration energy harvesting enhanced by using nonlinearity. Shock Vib. 2016, 2016, 3584740. [CrossRef]

138. Harris, P.; Arafa, M.; Litak, G.; Bowen, C.R.; Iwaniec, J. Output response identification in a multistable system for piezoelectric energy harvesting. Eur. Phys. J. B 2017, 90, 1-11. [CrossRef]

139. Pan, J.; Qin, W.; Deng, W. Promote efficiency of harvesting vibration energy by tailoring potential energy with addition of magnets. AIP Adv. 2019, 9, 075323. [CrossRef]

140. Shah, V.; Kumar, R.; Talha, M.; Twiefel, J. Numerical and experimental study of bistable piezoelectric energy harvester. Integr. Ferroelectr. 2019, 192, 38-56. [CrossRef]

141. Yao, M.; Ma, L.; Zhang, W. Study on power generations and dynamic responses of the bistable straight beam and the bistable L-shaped beam. Sci. China Technol. Sci. 2018, 61, 1404-1416. [CrossRef]

142. Zhang, X.; Yang, W.; Zuo, M.; Tan, H.; Fan, H.; Mao, Q.; Wan, X. An arc-shaped piezoelectric bistable vibration energy harvester: Modeling and experiments. Sensors 2018, 18, 4472. [CrossRef]

143. Ferrari, M.; Ferrari, V.; Guizzetti, M.; Andò, B.; Baglio, S.; Trigona, C. Improved energy harvesting from wideband vibrations by nonlinear piezoelectric converters. Sens. Actuators A Phys. 2010, 162, 425-431. [CrossRef]

144. Leng, Y.G.; Gao, Y.J.; Tan, D.; Fan, S.B.; Lai, Z.H. An elastic-support model for enhanced bistable piezoelectric energy harvesting from random vibrations. J. Appl. Phys. 2015, 117, 064901. [CrossRef]

145. Zhou, Z.; Qin, W.; Du, W.; Zhu, P.; Liu, Q. Improving energy harvesting from random excitation by nonlinear flexible bi-stable energy harvester with a variable potential energy function. Mech. Syst. Signal Process. 2019, 115, 162-172. [CrossRef]

146. Yang, W.; Towfighian, S. A hybrid nonlinear vibration energy harvester. Mech. Syst. Signal Process. 2017, 90, 317-333. [CrossRef]

147. Tang, Q.; He, Q.; Li, M.; Dong, C.; Xu, D.; Li, X. Wireless alarm microsystem self-powered by vibration-threshold-triggered energy harvester. IEEE Trans. Ind. Electron. 2016, 63, 2447-2456. [CrossRef]

148. Dorin, P.; Kim, J.; Wang, K.-W.; Erturk, A. Vibration energy harvesting system with coupled bistable modules. Proc. SPIE Int. Soc. Opt. Eng. 2019, 10967, 6.

149. Jiang, J.; Liu, S.; Zhao, D.; Feng, L. Broadband power generation of piezoelectric vibration energy harvester with magnetic coupling. J. Intell. Mater. Syst. Struct. 2019, 30, 2272-2282. [CrossRef]

150. Su, W.-J.; Zu, J.; Zhu, Y. Design and development of a broadband magnet-induced dual-cantilever piezoelectric energy harvester. J. Intell. Mater. Syst. Struct. 2013, 25, 430-442. [CrossRef]

151. Zhao, D.; Gan, M.; Zhang, C.; Wei, J.; Liu, S.; Wang, T. Analysis of broadband characteristics of two degree of freedom bistable piezoelectric energy harvester. Mater. Res. Express 2018, 5, 085704. [CrossRef]

152. Gao, Y.; Leng, Y.; Javey, A.; Tan, D.; Liu, J.; Fan, S.; Lai, Z. Theoretical and applied research on bistable dual-piezoelectric-cantilever vibration energy harvesting toward realistic ambience. Smart Mater. Struct. 2016, 25, 115032. [CrossRef]

153. Dehghani, R.; Khanlo, H.M. Radial basis function neural network chaos control of a piezomagnetoelastic energy harvesting system. J. Vib. Control 2019, 25, 2191-2203. [CrossRef]

154. Lu, Q.; Scarpa, F.; Liu, L.; Leng, J.; Liu, Y. An E-shape broadband piezoelectric energy harvester induced by magnets. J. Intell. Mater. Syst. Struct. 2018, 29, 2477-2491. [CrossRef]

155. Erturk, A.; Hoffmann, J.; Inman, D.J. A piezomagnetoelastic structure for broadband vibration energy harvesting. Appl. Phys. Lett. 2009, 94, 254102. [CrossRef]

156. Zhao, S.; Erturk, A. On the stochastic excitation of monostable and bistable electroelastic power generators: Relative advantages and tradeoffs in a physical system. Appl. Phys. Lett. 2013, 102, 103902. [CrossRef]

157. Erturk, A.; Inman, D.J. Broadband piezoelectric power generation on high-energy orbits of the bistable Duffing oscillator with electromechanical coupling. J. Sound Vib. 2011, 330, 2339-2353. [CrossRef]

158. Lan, C.; Qin, W. Enhancing ability of harvesting energy from random vibration by decreasing the potential barrier of bistable harvester. Mech. Syst. Signal Process. 2017, 85, 71-81. [CrossRef]

159. Zou, H.-X.; Zhang, W.-M.; Li, W.-B.; Wei, K.-X.; Gao, Q.-H.; Peng, Z.-K.; Meng, G. Design and experimental investigation of a magnetically coupled vibration energy harvester using two inverted piezoelectric cantilever beams for rotational motion. Energy Convers. Manag. 2017, 148, 1391-1398. [CrossRef]

160. Zhou, S.; Cao, J.; Lin, J.; Wang, Z. Exploitation of a tristable nonlinear oscillator for improving broadband vibration energy harvesting. Eur. Phys. J. Appl. Phys. 2014, 67, 30902. [CrossRef]

161. Cao, J.; Zhou, S.; Wang, W.; Lin, J. Influence of potential well depth on nonlinear tristable energy harvesting. Appl. Phys. Lett. 2015, 106, 173903. [CrossRef]

162. Haitao, L.; Weiyang, Q.; Chunbo, L.; Wangzheng, D.; Zhiyong, Z. Dynamics and coherence resonance of tri-stable energy harvesting system. Smart Mater. Struct. 2016, 25, 015001. [CrossRef]

163. Zhu, P.; Ren, X.; Qin, W.; Zhou, Z. Improving energy harvesting in a tri-stable piezomagnetoelastic beam with two attractive external magnets subjected to random excitation. Arch. Appl. Mech. 2016, 87, 45-57. [CrossRef]

164. Zhu, P.; Ren, X.; Qin, W.; Yang, Y.; Zhou, Z. Theoretical and experimental studies on thecharacteristics of a tri-stable piezoelectric harvester. Arch. Appl. Mech. 2017, 87, 1-14. [CrossRef] 
165. Lai, S.-K.; Wang, C.; Zhang, L.-H. A nonlinear multi-stable piezomagnetoelastic harvester array for low-intensity, low-frequency, and broadband vibrations. Mech. Syst. Signal Process. 2019, 122, 87-102. [CrossRef]

166. Wang, G.; Wu, H.; Liao, W.-H.; Cui, S.; Zhao, Z.; Tan, J. A modified magnetic force model and experimental validation of a tri-stable piezoelectric energy harvester. J. Intell Mater. Syst. Struct. 2020, 31, 967-979. [CrossRef]

167. Zhang, X.; Zuo, M.; Yang, W.; Wan, X. A tri-stable piezoelectric vibration energy harvester for composite shape beam: Nonlinear modeling and analysis. Sensors 2020, 20, 1370. [CrossRef] [PubMed]

168. Zhou, Z.; Qin, W.; Zhu, P. Improve efficiency of harvesting random energy by snap-through in a quad-stable harvester. Sens. Actuators A Phys. 2016, 243, 151-158. [CrossRef]

169. Zhou, Z.; Qin, W.; Zhu, P. A broadband quad-stable energy harvester and its advantages over bi-stable harvester: Simulation and experiment verification. Mech. Syst. Signal Process. 2017, 84, 158-168. [CrossRef]

170. Zhou, Z.; Qin, W.; Zhu, P. Harvesting performance of quad-stable piezoelectric energy harvester: Modeling and experiment. Mech. Syst. Signal Process. 2018, 110, 260-272. [CrossRef]

171. Zayed, A.A.A.; Assal, S.F.M.; Nakano, K.; Kaizuka, T.; El-Bab, A. Design procedure and experimental verification of a broadband quad-stable 2-DOF vibration energy harvester. Sensors 2019, 19, 2893. [CrossRef] [PubMed]

172. Kim, P.; Seok, J. A multi-stable energy harvester: Dynamic modeling and bifurcation analysis. J. Sound Vib. 2014, 333, 5525-5547. [CrossRef]

173. Wang, C.; Zhang, Q.; Wang, W. Low-frequency wideband vibration energy harvesting by using frequency up-conversion and quin-stable nonlinearity. J. Sound Vib. 2017, 399, 169-181. [CrossRef]

174. Zhou, Z.; Qin, W.; Yang, Y.; Zhu, P. Improving efficiency of energy harvesting by a novel penta-stable configuration. Sens. Actuators A Phys. 2017, 265, 297-305. [CrossRef]

175. Wang, G.; Liao, W.-H.; Zhao, Z.; Tan, J.; Cui, S.; Wu, H.; Wang, W. Nonlinear magnetic force and dynamic characteristics of a tri-stable piezoelectric energy harvester. Nonlinear Dyn. 2019, 97, 2371-2397. [CrossRef]

176. Tekam, G.T.O.; Kwuimy, C.A.; Woafo, P. Analysis of tristable energy harvesting system having fractional order viscoelastic material. Chaos 2015, 25, 013112. [CrossRef] [PubMed]

177. Xie, Z.; Kwuimy, C.; Wang, Z.; Huang, W. A piezoelectric energy harvester for broadband rotational excitation using buckled beam. AIP Adv. 2018, 8, 015125. [CrossRef]

178. Rashidi, R.; Summerville, N.; Nasri, M. Magnetically actuated piezoelectric-based rotational energy harvester with enhanced output in wide range of rotating speeds. IEEE Trans. Magn. 2019, 55, 8700208. [CrossRef]

179. Pozzi, M. Magnetic plucking of piezoelectric bimorphs for a wearable energy harvester. Smart Mater. Struct. 2016, 25, 1-17. [CrossRef]

180. Dauksevicius, R.; Kleiva, A.; Grigaliunas, V. Analysis of magnetic plucking dynamics in a frequency up-converting piezoelectric energy harvester. Smart Mater. Struct. 2018, 27, 085016. [CrossRef]

181. Do, N.H.; Baek, Y.S. An eddy current-induced magnetic plucking for piezoelectric energy harvesting. Smart Mater. Struct. 2016, 25, 045021. [CrossRef]

182. Fang, S.; Fu, X.; Liao, W.-H. Asymmetric plucking bistable energy harvester: Modeling and experimental validation. J. Sound Vib. 2019, 459, 114852. [CrossRef]

183. Kan, J.; Fu, J.; Wang, S.; Zhang, Z.; Chen, S.; Yang, C. Study on a piezo-disk energy harvester excited by rotary magnets. Energy 2017, 122, 62-69. [CrossRef]

184. Ramezanpour, R.; Nahvi, H.; Ziaei-Rad, S. Electromechanical behavior of a pendulum-based piezoelectric frequency upconverting energy harvester. J. Sound Vib. 2016, 370, 280-305. [CrossRef]

185. Ramezanpour, R.; Nahvi, H.; Ziaei-Rad, S. Increasing the performance of a rotary piezoelectric frequency up-converting energy harvester under weak excitations. J. Vib. Acoust. 2017, 139, 011016. [CrossRef]

186. Shu, Y.C.; Wang, W.C.; Chang, Y.P. Electrically rectified piezoelectric energy harvesting induced by rotary magnetic plucking. Smart Mater. Struct. 2018, 27, 125006. [CrossRef]

187. Wu, W.-H.; Kuo, K.-C.; Lin, Y.-H.; Tsai, Y.-C. Non-contact magnetic cantilever-type piezoelectric energy harvester for rotational mechanism. Microelectron. Eng. 2018, 191, 16-19. [CrossRef]

188. Xie, X.D.; Wang, Q. A study on a high efficient cylinder composite piezoelectric energy harvester. Compos. Struct. 2017, 161, 237-245. [CrossRef]

189. Yeo, H.G.; Xue, T.; Roundy, S.; Ma, X.; Rahn, C.; Trolier-McKinstry, S. Strongly (001) oriented bimorph PZT film on metal foils grown by RF-sputtering for wrist-worn piezoelectric energy harvesters. Adv. Funct. Mater. 2018, 28, 1801327. [CrossRef]

190. Fu, H.; Yeatman, E.M. A methodology for low-speed broadband rotational energy harvesting using piezoelectric transduction and frequency up-conversion. Energy 2017, 125, 152-161. [CrossRef]

191. Xue, T.; Roundy, S. On magnetic plucking configurations for frequency up-converting mechanical energy harvesters. Sens. Actuators A Phys. 2017, 253, 101-111. [CrossRef]

192. Fu, H.; Yeatman, E.M. Rotational energy harvesting using bi-stability and frequency up-conversion for low-power sensing applications: Theoretical modelling and experimental validation. Mech. Syst. Signal Process. 2019, 125, 229-244. [CrossRef]

193. Jiang, X.-Y.; Zou, H.-X.; Zhang, W.-M. Design and analysis of a multi-step piezoelectric energy harvester using buckled beam driven by magnetic excitation. Energy Convers. Manag. 2017, 145, 129-137. [CrossRef] 
194. Ramezanpour, R.; Nahvi, H.; Ziaei-Rad, S. A vibration-based energy harvester suitable for low-frequency, high-amplitude environments: Theoretical and experimental investigations. J. Intell. Mater. Syst. Struct. 2015, 27, 642-665. [CrossRef]

195. Hu, X.; Li, Y.; Xie, X. A study on a U-shaped piezoelectric coupled beam and its corresponding ingenious harvester. Energy 2019, 185, 938-950. [CrossRef]

196. Zou, H.-X.; Zhang, W.-M.; Li, W.-B.; Gao, Q.-H.; Wei, K.-X.; Peng, Z.-K.; Meng, G. Design, modeling and experimental investigation of a magnetically coupled flextensional rotation energy harvester. Smart Mater. Struct 2017, 26, 115023. [CrossRef]

197. Kuang, Y.; Yang, Z.; Zhu, M. Design and characterisation of a piezoelectric knee-joint energy harvester with frequency upconversion through magnetic plucking. Smart Mater. Struct. 2016, 25, 085029. [CrossRef]

198. Fan, K.; Tan, Q.; Liu, H.; Zhu, Y.; Wang, W.; Zhang, D. Hybrid piezoelectric-electromagnetic energy harvester for scavenging energy from low-frequency excitations. Smart Mater. Struct. 2018, 27, 085001. [CrossRef]

199. Halim, M.A.; Kabir, M.H.; Cho, H.; Park, J.Y. A frequency up-converted hybrid energy harvester using transverse impact-driven piezoelectric bimorph for human-limb motion. Micromachines 2019, 10, 701. [CrossRef] [PubMed]

200. Ibrahim, M.; Salehian, A. Modeling, fabrication, and experimental validation of hybrid piezo-magnetostrictive and piezomagnetic energy harvesting units. J. Intell. Mater. Syst. Struct. 2014, 26, 1259-1271. [CrossRef]

201. Xu, Z.; Shan, X.; Chen, D.; Xie, T. A novel tunable multi-frequency hybrid vibration energy harvester using piezoelectric and electromagnetic conversion mechanisms. Appl. Sci. 2016, 6, 10. [CrossRef]

202. Xu, Z.; Wang, W.; Xie, J.; Xu, Z.; Zhou, M.; Yang, H. An impact-based frequency up-converting hybrid vibration energy harvester for low frequency application. Energies 2017, 10, 1761. [CrossRef]

203. Yang, T.; Cao, Q. Dynamics and performance evaluation of a novel tristable hybrid energy harvester for ultra-low level vibration resources. Int. J. Mech. Sci. 2019, 156, 123-136. [CrossRef]

204. Zhang, G.; Gao, S.; Liu, H.; Zhang, W. Design and performance of hybrid piezoelectric-electromagnetic energy harvester with trapezoidal beam and magnet sleeve. J. Appl. Phys. 2019, 125, 084101. [CrossRef]

205. Xu, Z.; Shan, X.; Yang, H.; Wang, W.; Xie, T. Parametric analysis and experimental verification of a hybrid vibration energy harvester combining piezoelectric and electromagnetic mechanisms. Micromachines 2017, 8, 189. [CrossRef]

206. Sriramdas, R.; Pratap, R. An experimentally validated lumped circuit model for piezoelectric and electrodynamic hybrid harvesters. IEEE Sens. J. 2018, 18, 2377-2384. [CrossRef]

207. Salim, M.; Dayou, J.; Aljibori, H.S.; Salim, D.; Shebeeb, A. A low frequency hybrid harvester with ring magnets. Sustain. Energy Technol. 2016, 13, 23-30. [CrossRef]

208. Yu, H.; Zhou, J.; Yi, X.; Wu, H.; Wang, W. A hybrid micro vibration energy harvester with power management circuit. Microelectron. Eng. 2015, 131, 36-42. [CrossRef]

209. Rajarathinam, M.; Ali, S.F. Energy generation in a hybrid harvester under harmonic excitation. Energy Convers. Manag. 2018, 155, 10-19. [CrossRef]

210. Xu, Z.; Yang, H.; Zhang, H.; Ci, H.; Zhou, M.; Wang, W.; Meng, A. Design and analysis of a magnetically coupled multi-frequency hybrid energy harvester. Sensors 2019, 19, 3203. [CrossRef] [PubMed]

211. Fan, K.; Liu, S.; Liu, H.; Zhu, Y.; Wang, W.; Zhang, D. Scavenging energy from ultra-low frequency mechanical excitations through a bi-directional hybrid energy harvester. Appl. Energy 2018, 216, 8-20. [CrossRef]

212. Zhou, X.; Gao, S.; Liu, H.; Jin, L. Nonlinear hybrid piezoelectric and electromagnetic energy harvesting driven by colored excitation. Energies 2018, 11, 498. [CrossRef]

213. Bianconi, J.; Hallett, J.; Pealo, J.; Rashidi, R. A hybrid piezoelectric and inductive rotational energy harvester. IOP Conf. Ser. Mater. Sci. Eng. 2019, 626, 012004. [CrossRef]

214. Li, Z.; Li, T.; Yang, Z.; Naguib, H.E. Toward a $0.33 \mathrm{~W}$ piezoelectric and electromagnetic hybrid energy harvester: Design, experimental studies and self-powered applications. Appl. Energy 2019, 255, 113805. [CrossRef]

215. Toyabur, R.M.; Salauddin, M.; Cho, H.; Park, J.Y. A multimodal hybrid energy harvester based on piezoelectric-electromagnetic mechanisms for low-frequency ambient vibrations. Energy Convers. Manag. 2018, 168, 454-466. [CrossRef]

216. Li, P.; Gao, S.; Zhou, X.; Liu, H. On the performances of a nonlinear hybrid piezoelectric and electromagnetic energy harvester. Microsyst. Technol. 2017, 24, 1017-1024. [CrossRef]

217. Xia, H.; Chen, R.; Ren, L. Parameter tuning of piezoelectric-electromagnetic hybrid vibration energy harvester by magnetic force: Modeling and experiment. Sens. Actuators A Phys. 2017, 257, 73-83. [CrossRef]

218. Khalid, S.; Raouf, I.; Khan, A.; Kim, N.; Kim, H.S. A review of human-powered energy harvesting for smart electronics: Recent progress and challenges. Int. J. Precis. Eng. Manuf. Green Technol. 2019, 6, 821-851. [CrossRef]

219. Zuo, L.; Tang, X. Large-scale vibration energy harvesting. J. Intell. Mater. Syst. Struct. 2013, 24, 1405-1430. [CrossRef]

220. Karami, M.A.; Inman, D.J. Powering pacemakers from heartbeat vibrations using linear and nonlinear energy harvesters. Appl. Phys. Lett. 2012, 100, 042901-042904. [CrossRef]

221. Pillatsch, P.; Yeatman, E.M.; Holmes, A.S. A piezoelectric frequency up-converting energy harvester with rotating proof mass for human body applications. Sens. Actuators A Phys. 2014, 206, 178-185. [CrossRef]

222. Xue, T.; Yeo, H.G.; Trolier-McKinstry, S.; Roundy, S. Wearable inertial energy harvester with sputtered bimorph lead zirconate titanate (PZT) thin-film beams. Smart Mater. Struct. 2018, 27, 085026. [CrossRef]

223. Izadgoshasb, I.; Lim, Y.Y.; Tang, L.; Padilla, R.V.; Tang, Z.S.; Sedighi, M. Improving efficiency of piezoelectric based energy harvesting from human motions using double pendulum system. Energy Convers. Manag. 2019, 184, 559-570. [CrossRef] 
224. Zhang, Y.; Zheng, R.; Kaizuka, T.; Su, D.; Nakano, K. Study on tire-attached energy harvester for low-speed actual vehicle driving. J. Phys. Conf. Ser. 2015, 660, 012126. [CrossRef]

225. Janphuang, P.; Lockhart, R.A.; Isarakorn, D.; Henein, S.; Briand, D.; de Rooij, N.F. Harvesting energy from a rotating gear using an AFM-like MEMS piezoelectric frequency up-converting energy harvester. J. Microelectromech. Syst. 2015, 24, 742-754. [CrossRef]

226. Cho, J.Y.; Jeong, S.; Jabbar, H.; Song, Y.; Ahn, J.H.; Kim, J.H.; Jung, H.J.; Yoo, H.H.; Sung, T.H. Piezoelectric energy harvesting system with magnetic pendulum movement for self-powered safety sensor of trains. Sens. Actuators A Phys. 2016, 250, 210-218. [CrossRef]

227. Yuan, G.; Zhuo, S.; Wang, D. Nonlinear arbitrary-directional broadband piezoelectric vibration energy harvester using 3-DOF parallel mechanism. Smart Mater. Struct. 2019, 28, 085016. [CrossRef]

228. Yarar, E.; Meyners, D.; Quandt, E.; Fichtner, S.; Hayes, P.; Piorra, A.; Reimer, T.; Lisec, T.; Frank, P.; Wagner, B.; et al. MEMS-based AlScN resonating energy harvester with solidified powder magnet. J. Microelectromech. Syst. 2019, 28, 1019-1031. [CrossRef]

229. Vargas, C.A.; Tinoco, H.A. Electrical performance of a piezo-inductive device for energy harvesting with low-frequency vibrations. Actuators 2019, 8, 55. [CrossRef]

230. Yang, W.; Towfighian, S. Low frequency energy harvesting with a variable potential function under random vibration. Smart Mater. Struct. 2018, 27, 114004. [CrossRef]

231. Jia, Y. Review of nonlinear vibration energy harvesting: Duffing, bistability, parametric, stochastic and others. J. Intell. Mater. Syst. Struct. 2020, 31, 921-944. [CrossRef]

232. Siddique, A.R.M.; Mahmud, S.; Heyst, B.V. A comprehensive review on vibration based micro power generators using electromagnetic and piezoelectric transducer mechanisms. Energy Convers. Manag. 2015, 106, 728-747. [CrossRef] 